\title{
Optimizing internal wave drag in a forward barotropic model with semidiurnal tides
}

\author{
M.C. Buijsman ${ }^{\text {a,* }}$, B.K. Arbic ${ }^{\text {b }}$, J.A.M. Green ${ }^{c}$, R.W. Helber ${ }^{\text {d }}$, J.G. Richman ${ }^{\text {d }}$, J.F. Shriver ${ }^{\text {d }}$, P.G. Timko ${ }^{c}$, \\ A. Wallcraft ${ }^{\mathrm{d}}$ \\ ${ }^{a}$ University of Southern Mississippi, Stennis Space Center, MS, USA \\ ${ }^{\mathrm{b}}$ University of Michigan, Ann Arbor, MI, USA \\ ${ }^{\mathrm{c}}$ Bangor University, Menai Bridge, Anglesey, UK \\ ${ }^{\mathrm{d}}$ U.S. Naval Research Laboratory, Stennis Space Center, MS, USA
}

\section{A R T I C L E I N F O}

\section{Article history:}

Received 28 April 2014

Received in revised form 31 August 2014

Accepted 5 November 2014

Available online 22 November 2014

\section{Keywords:}

Barotropic tides

Global modeling

Linear wave drag

\begin{abstract}
A B S T R A C T
A global tuning experiment for the semidiurnal tide is performed with a barotropic model. The model is forced with the $\mathrm{M}_{2}$ equilibrium tide and accounts for the self-attraction and loading (SAL) term. In addition to a quadratic drag, various linear internal wave drag terms adjusted by a scale factor of $\mathcal{O}(1)$ are applied. The drag terms include the original Nycander (2005) tensor scheme, the Nycander tensor scheme reduced at supercritical slopes, and their scalar sisters, a Nycander scalar scheme computed for additional abyssal hill roughness, and the Jayne and St. Laurent (2001) scalar scheme. The Nycander scheme does not have a tunable parameter, but to obtain the best tidal solutions, it is demonstrated that some tuning is unavoidable. It is shown that the scalar Nycander schemes yield slightly lower root-mean square (RMS) elevation errors vs. the data-assimilative TPXO tide model than the tensor schemes. Although the simulation with the optimally tuned original Nycander scalar yields dissipation rates close to TPXO, the RMS error is among the highest. The RMS error is lowered for the reduced schemes, which place relatively more dissipation in deeper water. The inclusion of abyssal hill roughness improves the regional agreement with TPXO dissipation rates, without changing the RMS errors. It is difficult to have each ocean basin optimally tuned with the application of a constant scale factor. The relatively high RMS error in the Atlantic Ocean is reduced with a spatially varying scale factor with a larger value in the Atlantic. Our best global mean RMS error of $4.4 \mathrm{~cm}$ for areas deeper than $1000 \mathrm{~m}$ and equatorward of $66^{\circ}$ is among the lowest obtained in a forward barotropic tide model.
\end{abstract}

(c) 2014 Elsevier Ltd. All rights reserved.

\section{Introduction}

The tidal motion of the world's oceans is powered by about 3.5 TW of energy input (Egbert and Ray, 2003). Initially it was believed that nearly all of this energy is dissipated through bottom friction in shallow coastal shelf seas where the barotropic tide velocities are large (Taylor, 1919). Hence, in early regional barotropic tide models, the tidal energy was dissipated with linearized or quadratic bottom drag that mostly operated in coastal oceans (Schwiderski, 1980; Le Provost et al., 1994). Often, the drag coefficients were tuned to improve the agreement with elevation observations.

Munk (1966) and Munk and Wunsch (1998) suggested, and indirectly showed, that there could be significant barotropic tidal

\footnotetext{
* Corresponding author. Tel.: +1 228688 2385; fax: +1 2286881121

E-mail address: maarten.buijsman@usm.edu (M.C. Buijsman).
}

dissipation in the abyssal ocean. Egbert and Ray (2000) inferred surface tide dissipation rates from an inverse barotropic tide model with assimilated satellite altimetry, and found that about a third of this barotropic tide dissipation occurs in the deep ocean, invalidating the early assumption that all tidal energy was dissipated in shallow water. Egbert and Ray (2000) associated the deep water dissipation with the energy transfer from the barotropic to the baroclinic tide at rough topography as suggested by Munk and Wunsch (1998). Linear theory for the generation of internal waves also predicts substantial barotropic tide dissipation in the deep ocean through the generation of internal tides (e.g. Nycander, 2005).

The energy conversion from the barotropic to the baroclinic tide at rough topography can be represented through the implementation of a linear wave drag (Stigebrandt, 1999). Jayne and St. Laurent (2001) applied a linear wave drag scheme in the momentum equation of a forward global barotropic tide model. This reduced the 
root-mean-square elevation error with observations from 16.4 to $10.1 \mathrm{~cm}$, when 8 tidal constituents were used. Moreover, the barotropic dissipation rates predicted with their linear wave drag scheme are in agreement with rates derived from TPXO - an inverse tidal solution based on altimetry (Egbert et al., 1994). Similarly, Egbert et al. (2004), Arbic et al. (2004) and Green and Nycander (2013), who applied forward barotropic tide models, and Lyard et al. (2006), who applied a data-assimilative barotropic tide model, also found that tidal elevations and energetics improved when internal wave drag schemes, with and without tunable parameters, were applied.

Some schemes, e.g. by Jayne and St. Laurent (2001) and Zaron and Egbert (2006), are based on a linear scaling relationship and rely on a tunable parameter. Other drag schemes, e.g. by Egbert et al. (2004), Garner (2005) and Nycander (2005), are derived from linear theory similar to Bell (1975) and do not have a tunable parameter. Green and Nycander (2013) show that without tuning, the Nycander parameterization in a barotropic model predicts global dissipation rates close to TPX07.2 rates. However, the use of schemes without a tunable parameter does not guarantee an optimal prediction of elevations and dissipation rates. For example, the dissipation rates and elevation root-mean-square errors may differ depending on the global bathymetry and stratification databases used. Another motivation for tuning is that the bathymetric databases do not resolve all abyssal features. Melet et al. (2013) demonstrated that the regional and global dissipation rates analytically computed with the Nycander scheme are increased due to the inclusion of abyssal hill roughness on ocean spreading ridges (Goff and Arbic, 2010). Moreover, a higher resolution bathymetric grid increases the linear wave drag strength (Nycander, 2005; Zilberman et al., 2009), implying the need for some tuning. Although the linear theory of these parameterizations is applicable from the acoustic limit (small excursion lengths) to quasi-steady flow (large excursion lengths) (Bell, 1975; Nycander, 2005), the theory breaks down on supercritical slopes, i.e. when the slope is steeper than the internal tide beam. Hence, these schemes overestimate the conversion at supercritical topography (Nycander, 2005). When a correction is applied at supercritical topography (Nikurashin and Ferrari, 2011; Scott et al., 2011) the overall drag is reduced (Melet et al., 2013), further justifying the application of a tunable parameter.

The schemes derived from linear theory by Bell (1975) are second order tensors, whereas the schemes based on a scaling relationship are scalars. The components of the tensor are functions of the directionality of the topographic roughness. As a consequence, dissipation strength is governed by the direction of the flow relative to the rough topography. In scalar schemes the dissipation is independent of the flow direction. According to Egbert et al. (2004), the scalar and tensor schemes they tested produced similar deep-water dissipation rates and patterns after tuning. This suggests that the directionality of the tensor scheme may not provide substantial additional benefit compared to the scalar schemes. This is relevant, because it is easier to implement a scalar than a tensor scheme in 3D models that have both tidal and atmospheric forcing (Arbic et al., 2010).

In this study we utilize the Nycander (2005) and Jayne and St. Laurent (2001) schemes, and their modifications, in global barotropic HYCOM forced with only the $\mathrm{M}_{2}$ tide. The $\mathrm{M}_{2}$ tide is the largest tidal constituent, comprising about $70 \%$ (2.4 TW) of the tidal energy input of 3.5 TW (Egbert and Ray, 2003). In comparison, the largest diurnal constituent, $\mathrm{K}_{1}$, contributes only $10 \%$ to the total input. We test the effects of the correction at supercritical slopes and the enhanced roughness due to abyssal hill topography on the wave drag strength. The effects of the additional roughness due to abyssal hill topography have been studied in a linear analytical model by Melet et al. (2013) and a numerical three-dimensional model by Timko et al. (2009) but never in a barotropic tide model. We perform a tuning experiment for each drag scheme to check if the lowest root-mean square (RMS) elevation errors versus the altimetry-constrained TPXO8-atlas and 151 pelagic tide gauges (Ray, 2013) coincide with the most optimal global, basin-wide, and regional dissipation rates based on the TPXO4, TPX06.2, TPXO7.2, and TPXO8-atlas inverse models. Although Green and Nycander (2013) compared the performance of the Jayne and St. Laurent (2001) and Nycander, 2005 schemes in a barotropic model, they did not explore whether their RMS elevation errors and dissipation rates could be improved by applying a scale factor. A better understanding of the performance of these internal wave drag schemes in tidal models is relevant for climate models that use similar parameterizations to represent the breaking of internal tides (Simmons et al., 2004b), which provide most of the vertical turbulent mixing in the deep ocean.

In the next section we discuss the model configuration, the linear wave drag schemes, and the model diagnostics. In the results section the model's elevation root-mean-square errors and dissipation rates are evaluated globally, per basin, and regionally. We finish in Section 4 with discussion and conclusions.

\section{Methodology}

\subsection{Ocean model configuration}

HYCOM is a community ocean model (http://hycom.org) that uses a generalized (hybrid isopycnal/terrain-following/z-level) vertical coordinate (Bleck, 2002). However, here we configure it for one layer and for tide forcing only. The generic one-layer shallow water momentum equation with tidal forcing and the continuity equation read

$\frac{\partial \mathbf{u}}{\partial t}+\mathbf{u} \cdot \nabla \mathbf{u}+f \mathbf{k} \times \mathbf{u}=-g \nabla\left(\eta-\eta_{\mathrm{EQ}}-\eta_{\mathrm{SAL}}\right)-\frac{C_{\mathrm{D}}|\mathbf{u}| \mathbf{u}}{H}-\chi \frac{\mathbb{C} \cdot \mathbf{u}}{H}-\mathcal{F}$

and

$\frac{\partial \eta}{\partial t}=-\nabla \cdot([H+\eta] \mathbf{u})$

where $t$ is time, $\mathbf{u}$ is the horizontal velocity vector, $\eta$ is the tidal elevation, $g$ is the gravitational acceleration, $f$ is the Coriolis parameter, $\mathbf{k}$ is the vertical unit vector, $H$ is the resting water depth, $C_{\mathrm{D}}$ is the quadratic bottom drag coefficient, $\mathbb{C}$ is a scalar or second-order tensor to represent the drag due to internal tide generation, $\chi$ a scale factor, $\mathcal{F}$ is the friction due to the eddy viscosity, and $\eta_{\mathrm{EQ}}$ and $\eta_{\mathrm{SAL}}$ respectively refer to the equilibrium tidal forcing and self attraction and loading term. The quadratic drag coefficient is 0.0025 in deep water and a function of depth in shallow water only when $C_{\mathrm{D}}=\left[\kappa / \log \left(0.5 \mathrm{H} / z_{0}\right)\right]^{2}>0.0025$ (Schlichting, 1968), with the von Karman coefficient $\kappa=0.4$ and the bottom roughness $z_{0}=10 \mathrm{~mm}$.

The model spans the entire globe north of $86^{\circ} \mathrm{S}$, with a Mercator grid from $66^{\circ} \mathrm{S}$ to $47^{\circ} \mathrm{N}$, at a resolution of $0.08^{\circ} \cos$ (latitude) by $0.08^{\circ}$ (latitude by longitude) and a bipolar Arctic patch north of $47^{\circ} \mathrm{N}$, i.e. the model uses a tripole grid (Murray, 1996). The meridional (latitudinal) grid resolution is held constant south of $66^{\circ} \mathrm{S}$ for computational efficiency. The average zonal (longitudinal) resolution varies from $9 \mathrm{~km}$ at the equator to $7 \mathrm{~km}$ at mid-latitudes (e.g. at $40^{\circ} \mathrm{N}$ ) and $3.5 \mathrm{~km}$ at the north pole. The bottom topography was constructed from the GEBCO_08 topographic database, version 20091120 (http://www.gebco.net), which has a resolution of 30 arc seconds. However, in the deep ocean the effective resolution is much coarser, and abyssal hills on ocean spreading ridges are not resolved (Goff and Arbic, 2010). The model's land-sea boundary is at the $0-\mathrm{m}$ isobath but depths shallower than $5 \mathrm{~m}$ are set to $5 \mathrm{~m}$. Numerous hand-edits have been performed to improve coastlines and sill depths in key straits and passages. In order to model the 
tides under the large Antarctic floating ice shelves, our bottom topography south of $60^{\circ} \mathrm{S}$ and shallower than $1200 \mathrm{~m}$ is merged with bathymetry used in Arbic et al. (2004), which treats the extent of the water under the shelf as the ocean depth.

The model is forced with the principal lunar semidiurnal $\mathrm{M}_{2}$ tide with nodal corrections (Pugh, 1987). It is spun up from December 1, 2003 and run with various internal wave drag schemes. Each simulation lasts 33 days, with hourly elevation and velocity data saved for the last three days. These are run through a harmonic analysis tool (Foreman, 1977) to obtain amplitudes and phases independent of the nodal correction. In most grid points the fit is excellent, with about $99.9 \%$ of the variance explained by the $\mathrm{M}_{2}$ tide. The harmonic constants are used to compute root-mean square errors or synthetic time series from which offline dissipation rates are computed.

\subsection{Implementation of self-attraction and loading}

Hendershott (1972) showed that global numerical tide models must account for self-gravitation of the ocean tide, solid earth deformation due to the load of the ocean tide, and perturbations to the gravitational potential due to the self-gravitation of the solid earth thus deformed. Collectively, these terms are known as the self-attraction and loading (SAL) term. A complete treatment of the SAL term requires computing a spherical harmonic decomposition of the ocean tide (see e.g. Ray, 1998; Egbert et al., 2004). This is not computationally feasible to do in the model as it runs, and is instead done offline. A simpler approach is to use the scalar approximation, in which the SAL term is approximated as a constant times the sea surface elevation field $\left(\eta_{\mathrm{SAL}} \approx \beta \eta\right)$. The scalar approximation is significantly less accurate than the spherical harmonic treatment, and is not accurate enough for many global tide applications (Ray, 1998). In this study we use a spatially varying scalar approximation that is based on the TPXO8-atlas $\mathrm{M}_{2}$ SAL amplitude divided by the TPXO8-atlas $\mathrm{M}_{2}$ tide amplitude (http:// volkov.oce.orst.edu/tides/tpxo8atlas.html), with some spatial smoothing. We selected this tide atlas because it is widely used and it has low RMS errors with tidal pressure recorder and tide gauge stations (Stammer et al., 2014). However, we could have used any of the other atlases from the data-assimilative models compared by Stammer et al. (2014) because their tidal elevations are very similar, in particular in deep water (Table 3 of Stammer et al. (2014)). The SAL amplitude is directly computed from the TPX08-atlas $\mathrm{M}_{2}$ tide using spherical harmonics. For selected simulations, we employ an iterative procedure to achieve numerical convergence between the tidal elevations and SAL, similar to the method used by Accad and Pekeris (1978), Arbic et al. (2004), Egbert et al. (2004) and Lyard et al. (2006). While the initial simulation uses the spatially varying scalar SAL, all subsequent iterations use the full SAL term with spatially varying amplitudes and phases computed using spherical harmonics and the tidal elevations from the previous iteration.

We assess the accuracy of the HYCOM simulations relative to the $\mathrm{M}_{2}$ TPXO8-atlas elevations in each grid cell for four cases: no SAL, a constant scalar SAL with $\beta=0.095$, a value that gives the best agreement between the model and TPXO, spatially varying SAL, and iterated SAL. The measure for the accuracy is defined as

$R M S E_{t}=\sqrt{\left\langle\left[\eta_{\mathrm{m}}(t)-\eta_{\mathrm{T}}(t)\right]^{2}\right\rangle}$,

where $\eta$ is the elevation, subscripts " $m$ " and " $T$ " refer to model and TPXO, $t$ is time, and \langle\rangle indicate time averaging. Fig. 1 shows the percentage of the global surface area where area-weighted $R M S E_{t}$ is less than the $x$-axis value for the four cases. In these HYCOM simulations the linear wave drag by Jayne and St. Laurent (2001) is applied. Fig. 1 illustrates that a conventional globally constant

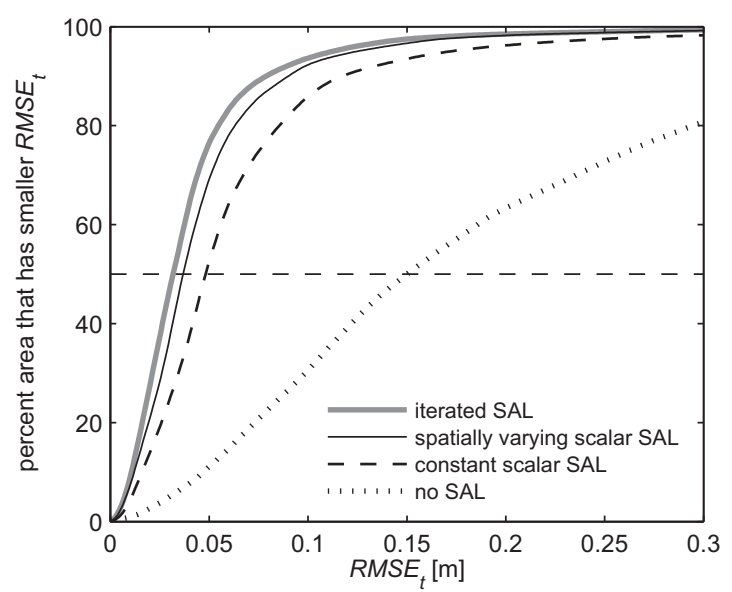

Fig. 1. Global percentile of HYCOM sea surface height root-mean-square in time error versus TPXO8-atlas for the best performing JSL scheme with scale factor $=0.375$.

scalar SAL (median error $4.9 \mathrm{~cm}$ ) is substantially better than no SAL (median error $15 \mathrm{~cm}$ ), but still quite different to the iterated $\mathrm{SAL}$ (median error $3.2 \mathrm{~cm}$ ). The spatially varying scalar SAL (median error $3.7 \mathrm{~cm}$ ) is closer to the iterated SAL and in particular it agrees well when $R M S E_{t}$ is large.

Motivated by the above results, the drag tuning runs all use the spatially varying scalar SAL. The tuning with the best-performing wave drag schemes are then repeated with iterated SAL, without significantly altering the tuning result. This selective approach also saves time and effort. Generally, only one iteration is needed to reach sufficient accuracy.

\subsection{Internal wave drag schemes}

We test the response of HYCOM to various drag schemes modified using a range of scale factors (see Table 1 for a summary).

\subsubsection{Nycander parameterization}

Tensor The tensor scheme of Nycander (2005), with units of $\mathrm{m} \mathrm{s}^{-1}$, is given by

$\mathbb{C}=\frac{N_{\mathrm{b}}}{4 \pi} \sqrt{1-\frac{f^{2}}{\omega^{2}}}(\nabla h \nabla J+\nabla J \nabla h)$,

where $N_{\mathrm{b}}$ is the buoyancy frequency at the bottom, $f$ is the Coriolis frequency, $\omega$ is a tidal frequency, $h=-H$ is the bottom topography (increasing upward), and $J$ is a double integral of the topographic height and a filtered Green's function. In this scheme $\mathbb{C}$ is set to zero poleward of the turning latitudes where $\omega=f$. The buoyancy frequency at the bottom is computed using the GDEM4 global monthly temperature and salinity climatology database (Carnes et al., 2010), which is constructed from historical in situ ocean observations. In our computation of $\mathbb{C}$, we follow the same approach as in Green and Nycander (2013). Before we compute the roughness $\nabla h \nabla J$, we first average the GEBCO_08 grid to 60 s to reduce computation time. We refer to this set-up as "NC tensor".

Scalar. The tensor drag can be transformed into a scalar

$C_{\mathrm{NC}}=\frac{\langle\mathbf{u} \cdot \mathbb{C} \cdot \mathbf{u}\rangle}{\left\langle|\mathbf{u}|^{2}\right\rangle}$

by equating the energy dissipation due to the tensor with the energy dissipation due to the scalar (Arbic et al., 2010). We use the TPXO8-atlas velocities for this purpose. We refer to this as "NC scalar". 
Table 1

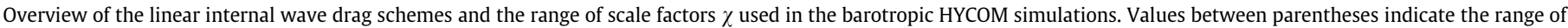
scale factors used in selected simulations with iterated SAL. SSG is the SRTM30_PLUS bathymetry with added abyssal hill roughness.

\begin{tabular}{|c|c|c|c|c|}
\hline Drag scheme & Type & Characteristics & $\chi$ range & Name \\
\hline Nycander (2005) & Tensor & Full & $0.5-4$ & NC tensor \\
\hline Nycander (2005) & Scalar & Full & $0.5-4$ & NC scalar \\
\hline Nycander (2005) & Tensor & Reduced at supercr. slopes & $0.5-5$ & NC tensor red \\
\hline Nycander (2005) & Scalar & Reduced at supercr. slopes & $0.5-6(1-4)$ & NC scalar red \\
\hline Nycander (2005) & Scalar & SSG, reduced at supercr. slopes & $2-5(2-3.5)$ & NC scalar SSG red \\
\hline Jayne and St. Laurent (2001) & Scalar & Limited above $-1000 \mathrm{~m}$ & $0.25-0.75(0.25-0.5)$ & JSL \\
\hline
\end{tabular}

Reduction at Supercritical Slopes. Internal wave drag schemes are based on linear theory (Bell, 1975), and therefore only applicable to subcritical slopes. Subcritical slopes are flatter than the slope of the internal tide beam, whereas supercritical slopes are steeper. According to Nycander (2005), the application of his scheme overestimates the dissipation rates at supercritical topography. Consequently, Green and Nycander (2013) capped the tidal-mean dissipation rates at $1 \mathrm{~W} \mathrm{~m}^{-2}$ in their offline computations, whereas Green and David (2013) used 0.57C at supercritical slopes to match the dissipation rates with rates inferred from the TPXO8atlas in the South China Sea.

To compensate for the large drag at supercritical slopes, we follow the same approach as highlighted in Nikurashin and Ferrari (2011), Scott et al. (2011) and Melet et al. (2013), in which the drag strength at supercritical slopes is reduced by normalizing the drag by the criticality squared. The criticality

$\gamma=\sqrt{\frac{(\partial h / \partial x)^{2}+(\partial h / \partial y)^{2}}{\left(\omega^{2}-f^{2}\right) /\left(N_{b}^{2}-\omega^{2}\right)}}$

is the ratio of the topographic slope to the internal tide beam. The modified Nycander tensor and scalar drag schemes are referred to as "NC tensor red" and "NC scalar red".

Abyssal Hill Roughness. Finally, we compute a Nycander scalar for the bathymetry with additional artificial roughness due to the abyssal hills on mid-ocean spreading ridges (Goff and Arbic, 2010). High resolution bathymetries, such as GEBCO_08 and SRTM30_PLUS (Becker et al., 2009; Sandwell and Smith, 2009), are based on sparse mid-ocean measurements that do not capture these hills with wavelengths $<10 \mathrm{~km}$. Goff and Arbic (2010) computed a synthetic abyssal hill topography using statistical parameters of abyssal hill roughness derived from relationships between the average statistical properties of abyssal hills and the seafloor spreading rate and direction. The abyssal hill topography was merged with the $1 / 120^{\circ}$ SRTM30_PLUS bathymetry as discussed in Timko et al. (2009).

In this paper, we test how the drag, based on the SRTM30_PLUS merged with the abyssal hill bathymetry, affects the barotropic tides in HYCOM. SRTM30_PLUS and GEBCO_08 do not differ much for latitudes equatorward of $\sim 60^{\circ}$, the regions that see the strongest $\mathrm{M}_{2}$ internal tide generation. Poleward of $60^{\circ}$ there are height differences of $\pm 100 \mathrm{~m}$, but here the internal wave generation and associated wave drag are small. The bathymetry is averaged and subsampled to $1 / 60^{\circ}$ to speed up the drag computation. The drag strength of this scalar is reduced by normalizing by the criticality squared. We refer to this scalar drag as "NC scalar SSG red". Note that the model bathymetry is not updated with this rough bathymetry because the response of the flow to abyssal-hills subsampled on a $1 / 12^{\circ}$ grid is small.

\subsubsection{Jayne and St. Laurent parameterization}

The scalar linear wave drag term given by Jayne and St. Laurent (2001) reads
$C_{\mathrm{JSL}}=\frac{\pi}{L} \hat{H}^{2} N_{\mathrm{b}}$,

where $\hat{H}$ is the bottom roughness, $N_{\mathrm{b}}$ is the buoyancy frequency at the bottom, and $L$ is the wave length of the topography, set to $10 \mathrm{~km}$ in Jayne and St. Laurent (2001). For practical reasons $L$ is often used as tuning parameter, but we set it to $10 \mathrm{~km}$ and apply our independent scale factor. $\hat{H}$ is computed using the 30 arc seconds GEBCO_08 grid as the average squared depth anomaly over a $1^{\circ}$ square with respect to a plane fit. $N_{\mathrm{b}}$ is again computed using the GDEM4 database. In shallow water, in particular near shelf breaks, this drag scheme yields unrealistically high values that are an artifact of the plane fit method. The performance of the Jayne and St. Laurent scheme is greatly improved by setting drag in waters shallower than $1000 \mathrm{~m}$ to zero. We refer to this depth-limited scheme as "JSL". The results are not very sensitive to the size of the fit square. Experiments with a $0.5^{\circ}$ square yield results nearly identical to the $1^{\circ}$ square, but for a scale factor that is twice as large (results not shown).

Unlike the tensor by Nycander (2005), the JSL scalar is not bounded by any critical turning latitudes. Additional simulations are performed for the same scale factors (results not shown), in which $C_{\mathrm{JSL}}$ is scaled with $\sqrt{1-f^{2} / \omega_{2}^{2}}$, where $f$ and $\omega_{2}$ are the Coriolis and tidal $\mathrm{M}_{2}$ frequencies, and set to zero poleward of the $\mathrm{M}_{2}$ turning latitude of $75^{\circ}$. However, the exclusion of linear wave drag poleward of this turning latitude does not alter the elevation RMS errors and energy dissipation rates significantly compared to the simulations with the unbounded JSL scalar.

\subsection{Diagnostics}

The model simulations are validated against data-assimilative TPXO8-atlas sea surface heights, 151 deep-ocean-bottom-pressure-recorder stations (Ray, 2013; Stammer et al., 2014), energetics computed from TPXO8-atlas velocities, and TPXO dissipation rates.

\subsubsection{Sea surface height}

The advantage of using TPXO8-atlas, as compared to tide gauges, is that it covers the global ocean. The RMS error of TPXO8-atlas $\mathrm{M}_{2}$ elevations against the pelagic tide gauges is very low $-0.5 \mathrm{~cm}$ (Stammer et al., 2014). Hence, we assume that the TPXO8-atlas is the "truth" for the global ocean.

The most straightforward, but qualitative, comparison is a visual comparison of the simulated and the TPXO8-atlas $\mathrm{M}_{2}$ amplitudes and phases. We do this for the optimally tuned Nycander scheme with reduced strength at supercritical slopes, iterated SAL, and a scale factor of 2.75 in Fig. 2(a) and (b). Most amphidromic point locations are correctly simulated in the HYCOM simulations, except at the Antarctic coast near $200^{\circ}$ E. Similarly, HYCOM also captures the large amplitude regions in location and magnitude. The optimally tuned simulations for the other wave drag schemes display similar patterns (not shown for the sake of brevity). 

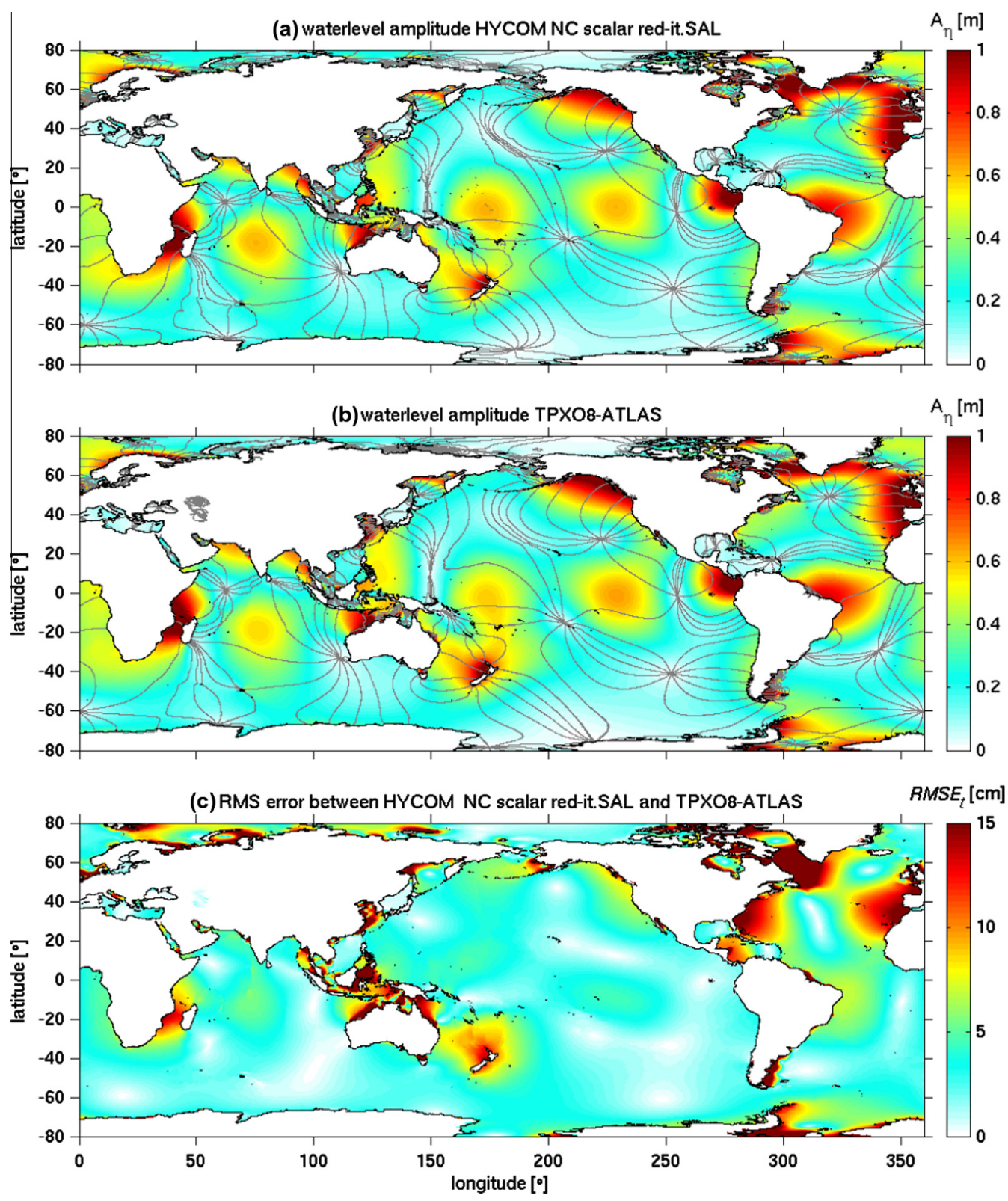

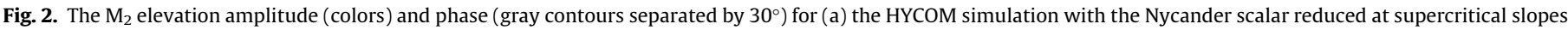
and a scale factor of 2.75 and iterated SAL and (b) the TPXO8-atlas. (c) The elevation RMS error between this HYCOM simulation and TPXO8-atlas.

The errors between the simulated and TPXO8-atlas elevations are quantified with the root-mean-square error averaged over time in each grid cell, $R M S E_{t}$ (Eq. (3)). The global $R M S E_{t}$ values for the optimum Nycander scheme are shown in Fig. 2(c). The largest errors tend to occur in coastal areas, where tidal amplitudes are largest. Of all the deep basins the North Atlantic has the largest error. Overall, the errors have become smaller compared to the $R M S E_{t}$ errors of the predecessor HYCOM simulations (Shriver et al., 2012). The southward extension of the model domain underneath the Antarctic floating ice shelves and the iterated SAL are the main causes of this reduction.

Global-mean RMS errors are computed in two ways in the literature. In the most common method, which is used in this paper, the time and area averaging of the squared difference is done before the square root is taken (Arbic et al., 2004)

$R M S E=\sqrt{\frac{\iint R M S E_{t}^{2} \mathrm{~d} A}{\iint \mathrm{d} A} .}$
Alternatively, the global mean RMS errors can be computed by areaaveraging the $R M S E_{t}$ error

$R M S E_{a}=\frac{\iint R M S E_{t} \mathrm{~d} A}{\iint \mathrm{d} A}$.

$R M S E_{a}$ is $2-3 \mathrm{~cm}$ smaller than RMSE when the coastal areas, which have the largest elevation errors, are included. The $R M S E_{a}$ is about $1 \mathrm{~cm}$ smaller than RMSE when the errors are computed for $H>1000 \mathrm{~m}$.

The long tail in Fig. 1 is caused by the high $R M S E_{t}$ in the coastal areas of the northern Atlantic (Fig. 2(c)), indicating $R M S E_{a}$ and RMSE may not be the best metrics for such a distribution. The median is a more robust metric but is more cumbersome to calculate compared to RMSE and $R M S E_{a}$, which are the most appropriate practical metrics. When the RMSE is computed for areas deeper than $1000 \mathrm{~m}$, the areas with the largest errors are omitted, and the RMSE is closer to the median of $R M S E_{t}$ for the entire global ocean. 
We interpolate the simulated tidal elevations at the locations of the 151 deep-ocean-bottom-pressure-recorder stations and compute $R M S E_{t}$ between the simulated and tide gauge elevations. The RMS error, $R M S E_{\mathrm{tg}}$, is calculated over all stations using (Eq. (8)). We only present $R M S E_{\mathrm{tg}}$ in Tables 2 and 3. The RMS errors presented in all figures are RMSE, computed using TPXO8-atlas elevations. In the tuning exercises, $R M S E_{\mathrm{tg}}$ shows the same trends as RMSE, but the former is about $2.5 \mathrm{~cm}$ larger than the latter because many of these gauges are in the northern Atlantic, where the model performance is weaker. Note that the optimum scale factors in Table 2 relate to the listed RMSE, but not necessarily to the listed $R M S E_{\mathrm{tg}}$, which optimum value may be off by one scale factor. Hence, the optimum $R M S E_{\mathrm{tg}}$ is slightly lower than the listed $R M S E_{\mathrm{tg}}$. This difference in optimal tuning can be attributed to the uneven distribution of the tide gauges over the global ocean.

\subsubsection{Energetics}

In addition to sea-surface height, we also use kinetic and available potential energy, as well as energy dissipation rates, to validate the simulations. We compute the time-mean and global integral of kinetic energy

$K E=\frac{1}{2} \rho_{0} \iint H\left\langle u^{2}+v^{2}\right\rangle \mathrm{d} A$,

where $u$ and $v$ are the zonal and meridional components of velocity, respectively, $\rho_{0}$ is the reference density, and $A$ is surface area, and available potential energy

$A P E=\frac{1}{2} g \rho_{0} \iint\left\langle\eta^{2}\right\rangle \mathrm{d} A$.

We compute these values offline using the HYCOM and TPXO8-atlas velocities and elevations.

The mean rate of working by the tidal forces, i.e. the tidal energy input (Egbert and Ray, 2001), is

$P=g \rho_{0} \iint\left\langle\eta_{\mathrm{EQ}} \frac{\partial \eta}{\partial t}\right\rangle \mathrm{d} A$,

where $\eta_{\mathrm{EQ}}$ is the equilibrium ocean tide height. The energy input should balance dissipation due to quadratic drag and linear wave drag and a small and ignored contribution of the horizontal eddy viscosity. The time-mean dissipation due to quadratic drag is

$D_{\mathrm{Q}}=\rho_{0} \iint\left\langle C_{\mathrm{D}}|\mathbf{u}|^{3}\right\rangle \mathrm{d} A$.

The time-mean dissipation due to linear wave drag is

$D_{\mathrm{L}}=\rho_{0} \iint\langle\mathbf{u} \cdot \mathbb{C} \cdot \mathbf{u}\rangle \mathrm{d} A$.

We verify that the global integral of the work done by the SAL term using (Eq. 12) is near zero $\left(<10^{-8} \mathrm{~W}\right)$. However, the regional work done by SAL, in particular in the coastal zones, can be larger than $0.05 \mathrm{~W} \mathrm{~m}^{-2}$, which is still an order of magnitude smaller than the input by the equilibrium tide. The spatial correlation between the two is small.

The energy input and dissipation due to quadratic and linear wave drag is computed online (Simmons et al., 2004a) and offline. The online rates still include the $\mathrm{M}_{2}$ nodal corrections for phase and amplitude $\left(\alpha_{\text {node }}=0.9752\right)$ for this particular simulation period. To compare with the offline and TPXO rates without nodal correction, we crudely correct the rates offline by multiplying (Eqs. (12)-(14)) with $\alpha_{\text {node }}^{-2}, \alpha_{\text {node }}^{-3}$, and $\alpha_{\text {node }}^{-2}$, respectively. The sum of the online quadratic and linear dissipation rates is larger than the global energy input by on average of $0.22 \mathrm{TW}$, while the sum of the offline rates is smaller than the global energy input by on average of $0.28 \mathrm{TW}$. We average the online and offline rates because this yields the best agreement between the energy input and dissipation.

Fig. 3(a) displays the sum of the online linear and quadratic drag dissipation rates for the optimal Nycander scheme with reduced drag strength at supercritical slopes. The dissipation due to linear wave drag is largest at the mid-ocean ridges and island chains, such as Hawaii, whereas the dissipation due to quadratic drag is largest in the coastal shelf seas such as the European shelf. The dissipation maps for the other drag schemes have a similar appearance, and are not shown for the sake of brevity.

TPXO does not assimilate tidal currents. Hence, its dissipation rates are not as reliable as its elevations. Nevertheless, we compare the simulated dissipation rates (Fig. 3(a)) with the TPXO dissipation rates (Fig. 3(b)). The latter rates are computed from the difference between the energy input and flux divergence as discussed in Egbert and Ray (2001) and Green and Nycander (2013). The energy input and flux divergence terms are one order of magnitude larger than the "residual" dissipation rate. As a consequence of this noisy process, the global dissipation maps have areas with negative rates (Fig. 3(b)) (Egbert and Ray, 2001; Egbert and Ray, 2003). Similar to the HYCOM dissipation rates in Fig. 3(a), the TPXO8-atlas dissipation rates are also large at rough topography and in coastal shelf seas. However, the deep-water dissipation rates are somewhat diffuse in Fig. 3(b) and the dissipation rates of TPXO8-atlas poorly resembles the dissipation rate due to the drag at the Mid-Atlantic Ridge. For this paper, we use dissipation rates inferred from the TPX06.2, TPX07.2, and TPXO8-atlas inverse models. Their range, as defined by their minimum and maximum values, is indicated in most figures with a light gray bar. The dissipation due to the latest tidal solution, TPXO8-atlas, is indicated with a dark gray bar.

\section{Results}

\subsection{Global response}

In this section, we consider the relation between the globally averaged RMS error on the one hand, and global energetics and dis-

Table 2

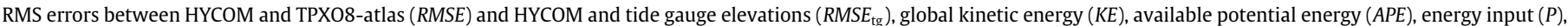

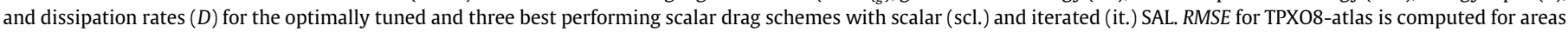

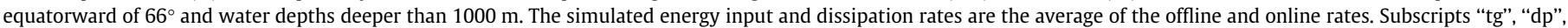
and "sh" refer to tide gauge, deep $(H>500 \mathrm{~m})$ and shallow $(H<500 \mathrm{~m})$, and "L" and "Q" to linear wave and quadratic bottom drag.

\begin{tabular}{|c|c|c|c|c|c|c|c|c|c|c|c|c|}
\hline SAL & Drag scheme & Scale factor & $R M S E[\mathrm{~cm}]$ & $R M S E_{\mathrm{tg}}[\mathrm{cm}]$ & $K E\left[10^{17} \mathrm{~J}\right]$ & APE $\left[10^{17} \mathrm{~J}\right]$ & $P[\mathrm{TW}]$ & $D[\mathrm{TW}]$ & $D_{\mathrm{dp}}[\mathrm{TW}]$ & $D_{\text {sh }}[\mathrm{TW}]$ & $D_{\mathrm{L}}[\mathrm{TW}]$ & $D_{\mathrm{Q}}[\mathrm{TW}]$ \\
\hline \multirow[t]{3}{*}{ scl. } & NC scalar red & 3.000 & 5.09 & 7.90 & 1.77 & 1.56 & 2.61 & 2.60 & 1.20 & 1.40 & 1.40 & 1.21 \\
\hline & NC scalar SSG red & 2.750 & 5.04 & 7.71 & 1.75 & 1.54 & 2.58 & 2.58 & 1.20 & 1.38 & 1.39 & 1.19 \\
\hline & JSL & 0.400 & 5.06 & 7.75 & 1.75 & 1.54 & 2.60 & 2.57 & 1.29 & 1.28 & 1.28 & 1.29 \\
\hline \multirow[t]{4}{*}{ it. } & NC scalar red & 2.750 & 4.43 & 7.10 & 1.73 & 1.52 & 2.50 & 2.49 & 1.08 & 1.41 & 1.26 & 1.23 \\
\hline & NC scalar SSG red & 2.500 & 4.46 & 6.99 & 1.72 & 1.51 & 2.49 & 2.47 & 1.08 & 1.40 & 1.25 & 1.22 \\
\hline & JSL & 0.375 & 4.46 & 7.01 & 1.69 & 1.49 & 2.49 & 2.45 & 1.17 & 1.28 & 1.16 & 1.29 \\
\hline & TPX08-atlas & - & - & - & 1.78 & 1.52 & 2.47 & 2.47 & 0.88 & 1.59 & - & - \\
\hline
\end{tabular}


Table 3

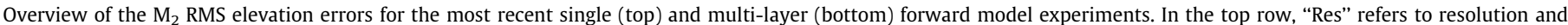

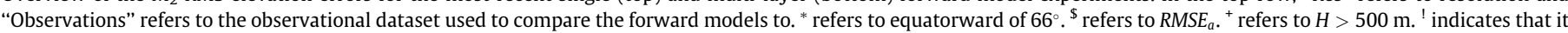

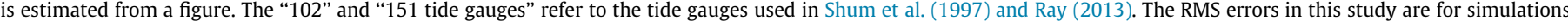
with iterated SAL.

\begin{tabular}{|c|c|c|c|c|c|c|}
\hline Study & Linear wave drag scheme & Model (layers) & $\operatorname{Res}\left[{ }^{\circ}\right]$ & Observations & $R M S E>1 \mathrm{~km}[\mathrm{~cm}]$ & $R M S E$ all depths $[\mathrm{cm}]$ \\
\hline Jayne and St. Laurent (2001) & JSL & $\mathrm{JSL}(1)$ & $1 / 2$ & UT-CSR & $6.7^{\$}$ & \\
\hline Egbert et al. (2004) & Bell & OTIS(1) & $1 / 12$ & TPXO5 & $\sim 5^{* ! !}$ & $\sim 9^{*, !}$ \\
\hline Green and Nycander, 2013 & Nycander & OTIS $(1)$ & $1 / 8$ & TPX07.2 & $7.0^{+}$ & \\
\hline This study & NC red & $\operatorname{HYCOM}(1)$ & $2 / 25$ & TPX08 & $4.4^{*}$ & $6.7^{*}$ \\
\hline This study & $\mathrm{NC}$ red & $\operatorname{HYCOM}(1)$ & $2 / 25$ & TPX08 & $3.6^{\$, *}$ & $4.3^{\S, *}$ \\
\hline This study & NC SSG red & $\operatorname{HYCOM}(1)$ & $2 / 25$ & 151 tide gauges & 7.0 & \\
\hline Arbic et al. (2004) & Garner & $\operatorname{HIM}(2)$ & $1 / 4$ & GOT99 & $7.3^{*}$ & \\
\hline Arbic et al. (2004) & none & $\operatorname{HIM}(2)$ & $1 / 4$ & GOT99 & $17.1^{*}$ & \\
\hline Simmons et al. (2004a) & none & $\operatorname{HIM}(2)$ & $1 / 8$ & GOT99 & $23.4^{*}$ & \\
\hline Arbic et al. (2010) & Garner & $\operatorname{HYCOM}(32)$ & $2 / 25$ & 102 tide gauges & 8.3 & \\
\hline Shriver et al. (2012) & Garner & HYCOM(32) & $2 / 25$ & TPX07.2 & $7.5^{\$, *}$ & \\
\hline Müller et al. (2012) & none & MPI-OM(40) & $1 / 10$ & 102 tide gauges & 8.2 & \\
\hline
\end{tabular}
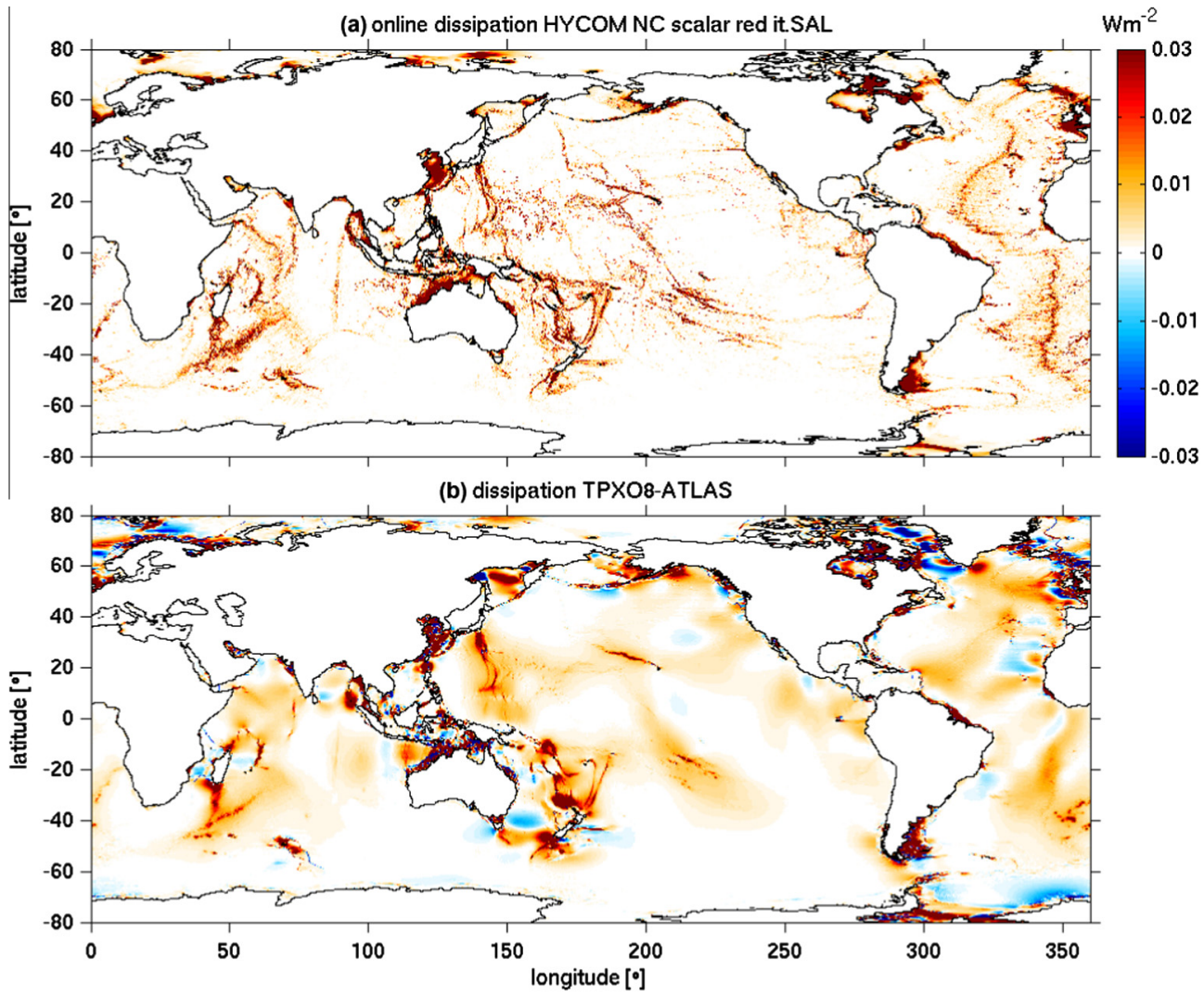

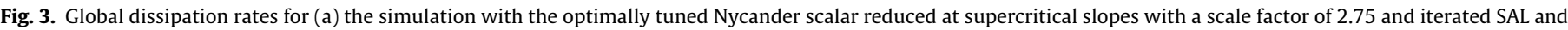
(b) TPX08-atlas.

sipation rates on the other, for various drag schemes and a range of scale factors.

\subsubsection{Kinetic and available potential energy}

As the scale factors increase, the kinetic and available potential energy decrease. Fig. 4 shows the global RMS errors below $1000 \mathrm{~m}$ and equatorward of $66^{\circ}$, which is the inclination of the orbit of the TOPEX/Poseidon and Jason altimeters. For small (large) scale factors, the linear wave drag dissipation in deep water is small (large), and the simulated amplitudes and energy of the tides are increased (decreased) relative to TPXO. Although their RMS errors differ, the energies of all optimally tuned schemes, i.e. those that have the lowest elevation RMS errors, are close to TPXO values (Fig. 4 and
Table 2). We later show that the locations of large tidal energy dissipation matter for the RMS error. Interestingly, the tensor scheme does not perform better than the scalar scheme. The scalar scheme has a slightly lower RMS error than the tensor. The Nycander scalar with reduced strength, the Nycander scalar with abyssal hills and reduced strength, and the JSL scheme perform nearly equally well and have about the same RMSE.

Repeating the tuning exercise for selected scale factors (Table 1 ) and iterating the SAL for the three best performing linear wave drag schemes, the reduced Nycander, the reduced Nycander with abyssal hills, and JSL, lowers the RMS errors by about $0.6-0.7 \mathrm{~cm}$, but barely affects the energy levels (Fig. 4 and Table 2). Although the optimally tuned simulations with iterated SAL have a smaller 

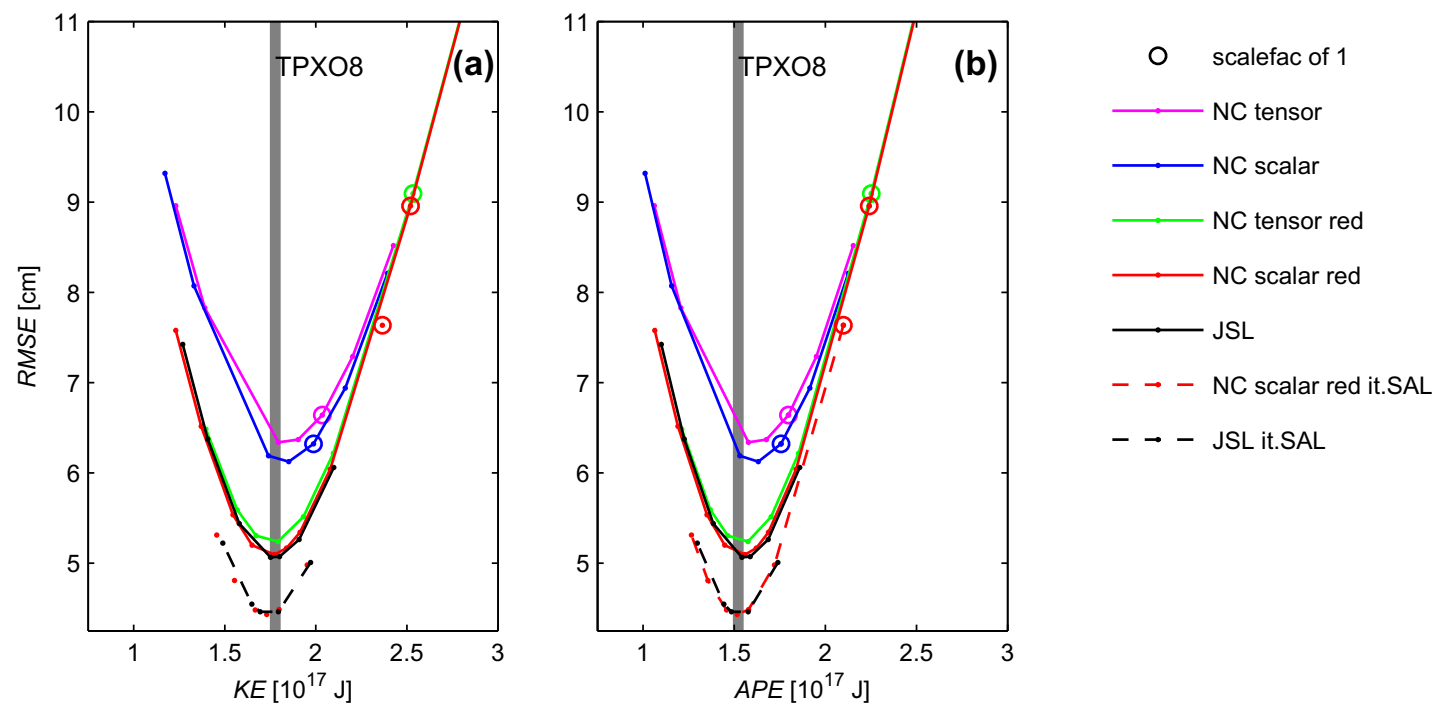

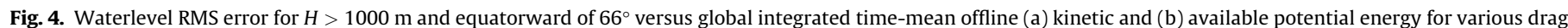

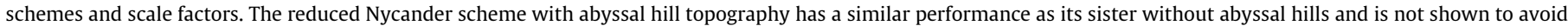

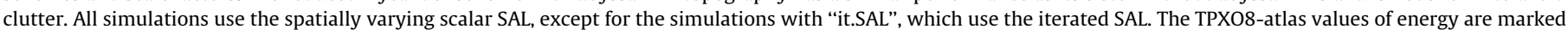
by the vertical gray bar. The kinetic and potential energy decrease for increasing scale factor.

scale factor than the simulations with the spatially varying scalar SAL (Table 2), the position of the parabola of the JSL scheme relative to the position of the parabola of the reduced Nycander scalar does not change substantially before and after iterating the SAL. This implies that we can use the faster spatially-varying-scalar SAL approach to compare the performance of the wave drag schemes relative to each other.

\subsubsection{Energy input and dissipation rates}

The simulations with the optimally tuned drag schemes, i.e. the simulations that have the lowest RMS error, have globally integrated energy input rates that are nearly equal to the globally integrated sum of the wave and bottom drag dissipation rates in Fig. 5 (the asterisks). However, their energy input is larger than the range of TPXO rates. Iterating the SAL for the Nycander scalar with reduced strength, the Nycander scalar with abyssal hills and reduced strength, and the JSL scheme improves the globally integrated energy input and dissipation rates relative to TPXO (red, cyan, and black crosses in Fig. 5). Although the HYCOM input/dissipation rates are close to the TPX08-atlas dissipation rate, with the reduced Nycander scalar with abyssal hills performing the best, we show in the next sections that the spatial dissipation distributions of the simulations differ from TPXO.

\subsubsection{Deep and shallow water dissipation rates}

While the sum of the linear and quadratic drag dissipation rates are within $\pm 0.1 \mathrm{TW}$ for all simulations in Fig. 5, the deep water $(H>500 \mathrm{~m})$ and shallow water $(H<500 \mathrm{~m})$ dissipation rates portray great variability for all drag schemes and scale factors as seen in Fig. 6(a) and (b). The deep water dissipation is mainly governed by the linear wave drag, whereas bottom drag comprises $80-90 \%$ of the dissipation in shallow water $(H<500 \mathrm{~m})$. Hence, an increase in the scale factor yields an increase in the deep water and a reduction in the shallow water dissipation.

The simulations with the untuned full Nycander tensor and scalar schemes with a spatially varying scalar SAL have dissipation rates within the range of TPXO values (iterating the SAL does not significantly change this). This result is in agreement with Green and Nycander (2013) who did not tune their Nycander tensor, although they limited peak drag values. The lowest RMS errors for the full Nycander tensor and scalar schemes are obtained with scale factors of 1.5 and 1.25 , respectively, which are still relatively close to unity.

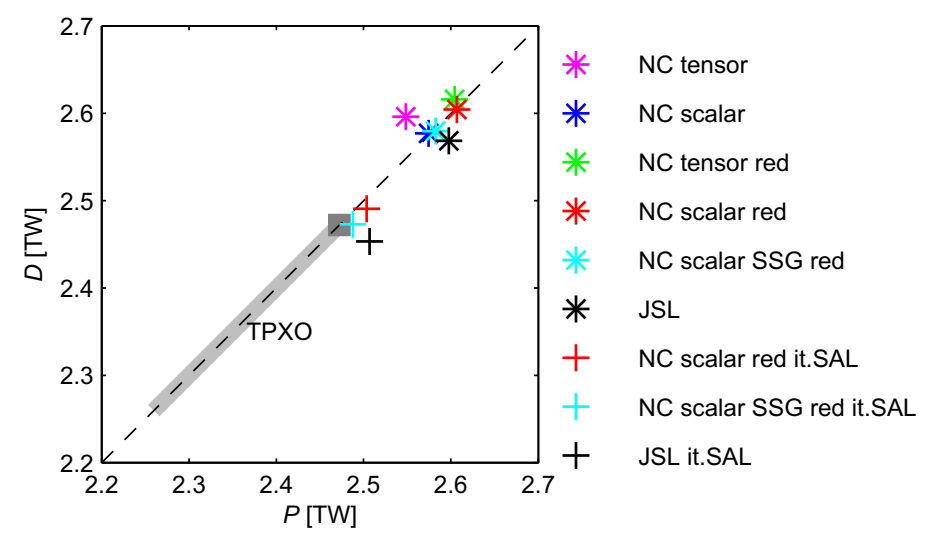

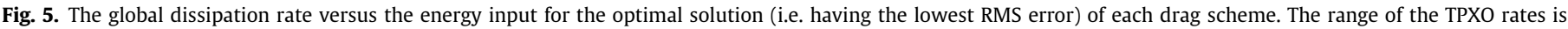
marked by the solid light gray line and TPXO8-atlas by the dark gray square. 
(a) Deep water; $H>500 \mathrm{~m}$

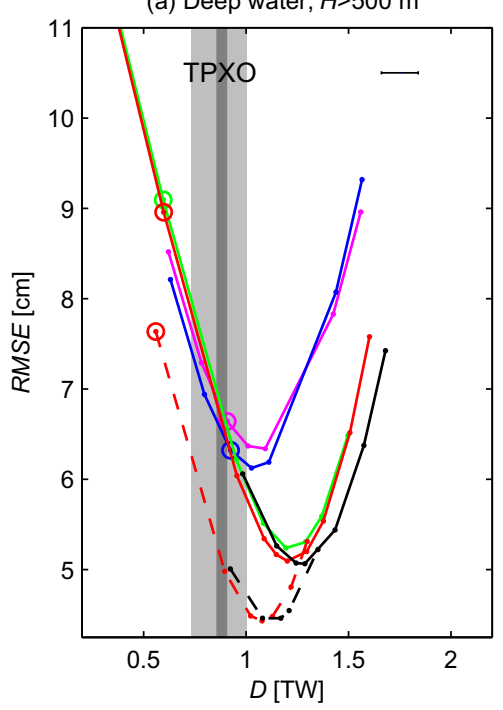

(b) Shallow water; $H<500 \mathrm{~m}$

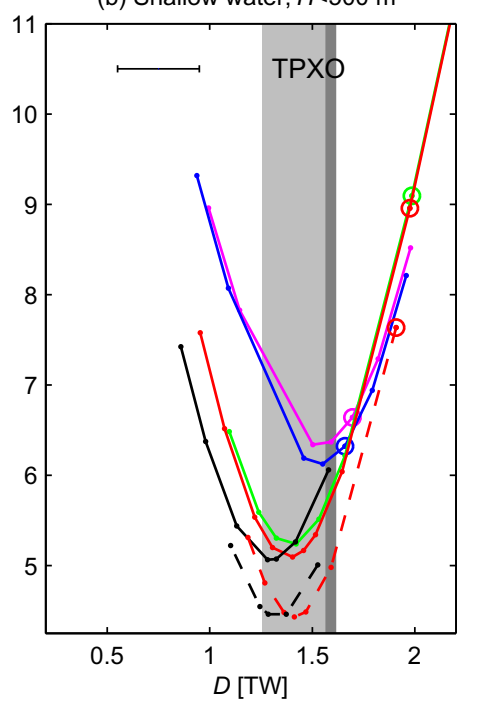

O scalefac of 1

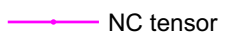

$\longrightarrow$ NC scalar

NC tensor red

$\longrightarrow$ NC scalar red

$\longrightarrow$ JSL

$-\rightarrow$ JSL it.SAL

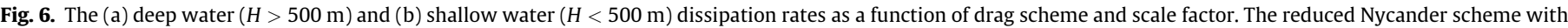

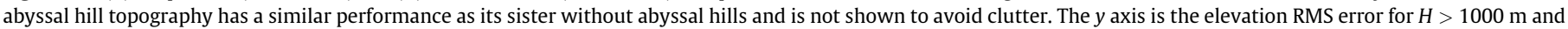

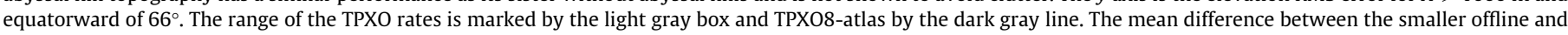

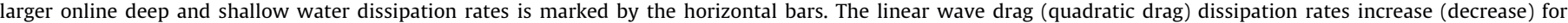
increasing scale factors.

For the two reduced Nycander schemes and the JSL scheme relatively more dissipation is placed in deep than in shallow water compared to the full Nycander schemes. The optimally tuned schemes have lower RMS errors, but more deep and less shallow water dissipation when compared to the TPXO values in Fig. 6(a) and (b).

Iterating the SAL for the JSL and the two reduced Nycander scalar schemes further lowers the RMS errors and also improves the deep and shallow water dissipation rates relative to TPXO (Fig. 6 and Table 2), but it is unable to remove the relative biases in the deep and shallow water dissipation rates. The ratio $D_{\text {shallow }} / D_{\text {deep }}$ is $1.31,1.30$ and 1.27 for the reduced Nycander scalar, the reduced Nycander scalar with abyssal hills and the JSL scalar, respectively. This ratio is smaller than for the TPXO8-atlas, which has $D_{\text {shallow }} / D_{\text {deep }}=1.81$ (Table 2). Although the RMSE for the three schemes are similar, the JSL scheme has larger and smaller deep and shallow water dissipation rates, respectively.

The TPXO dissipation rates do not differentiate between dissipation due to wave and bottom drag. Instead Egbert and Ray (2001) make a distinction between deep water (e.g. ocean ridges) and shallow water (coastal shelf areas) dissipation rates. Based on this distinction, it is generally assumed that all shallow water barotropic dissipation is due to quadratic bottom drag. This is largely confirmed by the HYCOM simulations, in which only about $13 \%$ of the shallow water dissipation is due to wave drag for the iterated and reduced Nycander schemes (Table 2). As a consequence, the dissipation due to wave drag is slightly larger than due to bottom drag. In contrast, for the depth-limited JSL scheme, all shallow water dissipation is due to bottom drag, and $D_{\text {shallow }} / D_{\text {deep }}$ and $D_{\mathrm{Q}} / D_{\mathrm{L}}$ are the same and both larger than unity.

\subsubsection{Dissipation rates as a function of depth}

In Fig. 7(a) we compare the area-integrated dissipation due to the linear wave and quadratic bottom drag, averaged over $100 \mathrm{~m}$ depth bins, for all optimally tuned Nycander and JSL scalars with TPXO. The simulation with the full Nycander scalar overpredicts the total TPXO dissipation between $\sim 2600$ and $200 \mathrm{~m}$ depth and underpredicts it in deeper water (blue line in Fig. 7(a)). The TPXO dissipation rate has a deep water maximum near $4000 \mathrm{~m}$ in
Fig. 7(a). This second maximum may be attributed to deep water ridges such as the Mid-Atlantic Ridge. The reduction of the drag at supercritical slopes shifts relatively more dissipation into deeper water and also yields a deep water maximum in dissipation (red line in Fig. 7(a)). However, the scheme causes too much energy dissipation between 3000 and $1500 \mathrm{~m}$ when compared to TPXO.

Iterating the SAL for the reduced Nycander scheme with and without abyssal hills further improves the dissipation rates relative to TPXO, but does not erase the mismatch at $2300 \mathrm{~m}$. The best agreement with TPXO is obtained for the simulation with abyssal hills, although its improvement relative to the reduced Nycander scheme without abyssal hills is modest.

Despite the fact that the simulation for the depth-limited JSL scheme with iterated SAL has similar elevation RMS errors as the reduced Nycander schemes, its barotropic energy dissipation distribution with depth differs (black dashed line in Fig. 7(a)). The absence of wave drag shallower than $1000 \mathrm{~m}$ reduces the dissipation rates between 700 and $150 \mathrm{~m}$ compared to the range of TPXO rates. The TPX08-atlas dissipation also has a distinct dip near $800 \mathrm{~m}$. However, this may be associated with the uncertainty in the TPXO dissipation computations. The absence of wave drag also causes relatively larger bottom drag dissipation rates shallower than $1000 \mathrm{~m}$ (Fig. 7(b)) and larger wave drag dissipation rates between 3000 and $2000 \mathrm{~m}$ (Fig. 7(a)). Moreover, the JSL scheme fails to predict the second maximum in deep water.

For the Nycander schemes in Fig. 7(b), and for waters shallower than $250 \mathrm{~m}$, the quadratic drag dissipation rates are larger than the linear wave drag dissipation rates. The absence of linear drag in waters shallower than $1000 \mathrm{~m}$ for the JSL scheme allows for relatively more quadratic drag dissipation than the Nycander schemes in water shallower than 1000 m (black dashed line in Fig. 7(b) and Table 2).

\subsection{Basin response}

We analyze the response of the RMS errors and dissipation rates to selected linear wave drag schemes for the three largest ocean basins: the Atlantic, the Pacific, and Indian oceans (Fig. 8). To avoid 


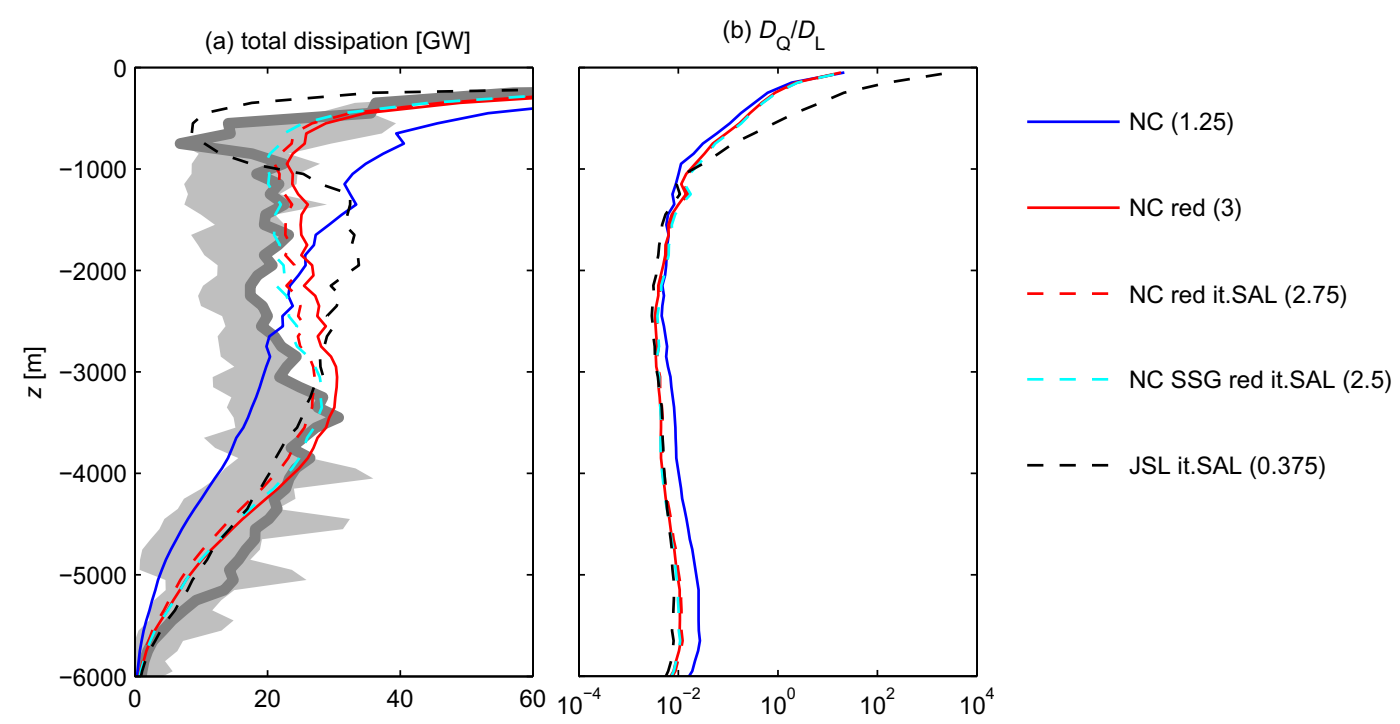

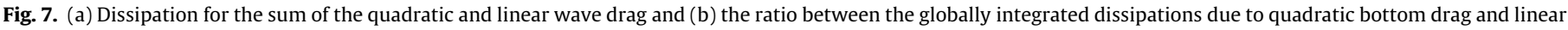

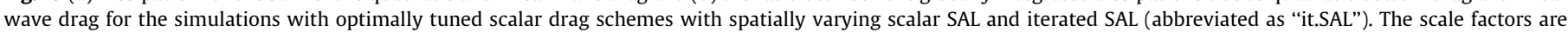
between parentheses. The range of the TPXO rates is marked by the light gray box and TPXO8-atlas by the dark gray line in (a).

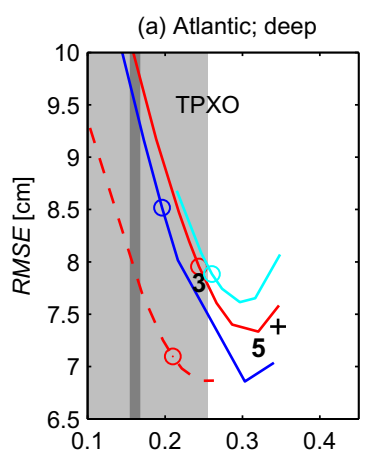

(b) shallow
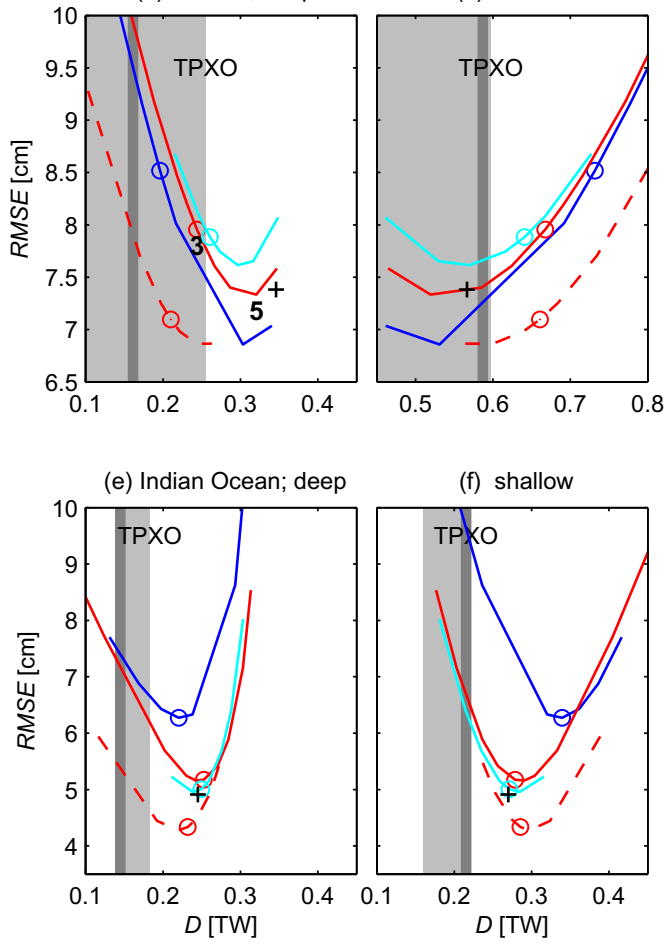

(f) shallow

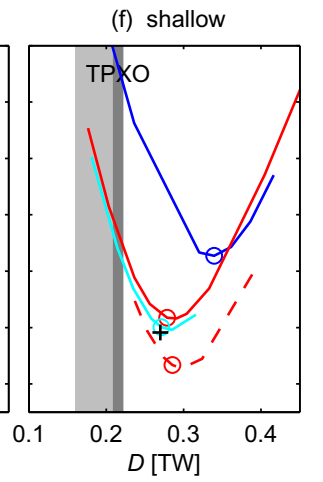

(c) Pacific; deep

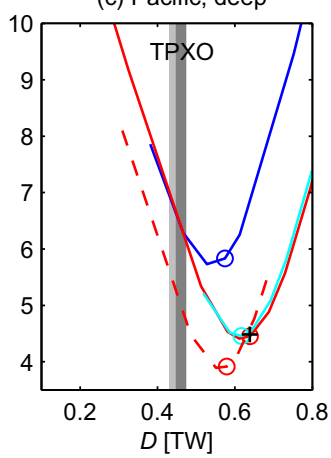

(d) shallow

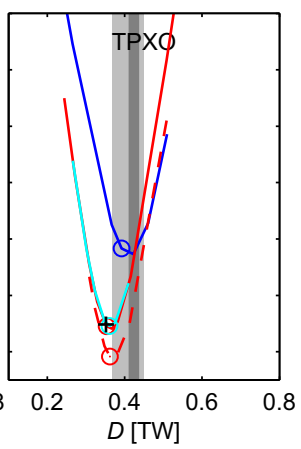

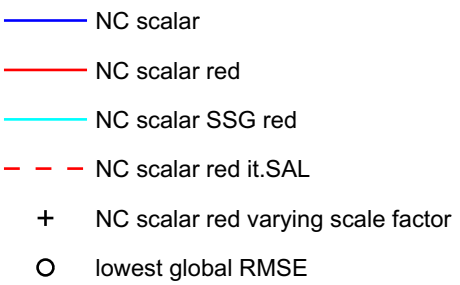

O lowest global RMSE

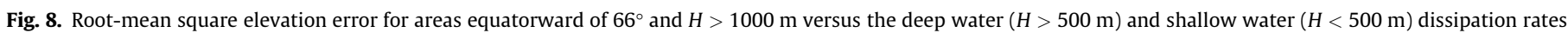

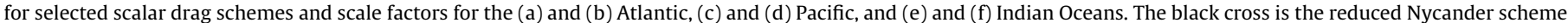

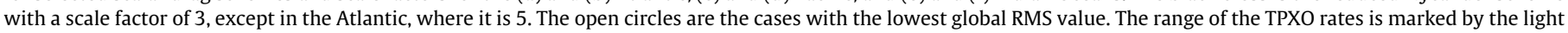
gray box and TPXO8-atlas by the dark gray line.

clutter, the tensors, the JSL scheme, and the reduced Nycander scalar with abyssal hills and iterated SAL are not plotted.

Compared to the other basins, the optimal solutions have the largest RMS errors in the Atlantic (the open circles in Fig. 8). This is also apparent in Fig. 2(c). Moreover, the optimal scale factors in a particular basin are different than the optimal scale factors for the global solution. This is particularly true for the Atlantic, where all drag schemes need a larger scale factor to obtain the lowest RMS error (i.e. the open circles do not coincide with the lowest RMSE in Fig. 8(a) and (b)). It may be that the bathymetry in the Atlantic is too smooth, causing an underestimation of the wave drag strength. For example, the reduced Nycander scalar has a global scale factor of 3, but its RMS error is at a minimum in the Atlantic for a scale factor of 5 (numbers near red line in Fig. 8(a)). For 
this scale factor the tidal solutions are poorer in the other basins, illustrating that improving the RMS in one basin by tuning may increase the RMS error in another. To check if the tidal solution improves when more drag is applied in the Atlantic, we perform one additional simulation for the reduced Nycander scalar scheme with a scale factor of 5 in the Atlantic and 3 in all other oceans (black cross in Fig. 8, compare to red circle). Indeed, the solution with the spatially varying scale factor is close to the optimum solution in all basins. The reduction in elevation RMSE is $0.6 \mathrm{~cm}$ in the Atlantic, with the strongest reduction occurring in the North Atlantic, where the RMSE is already large (Fig. 2(c)) The global elevation RMS error is reduced by $0.2 \mathrm{~cm}$ compared to the reduced Nycander scalar $(R M S E=5.09 \mathrm{~cm}$ in Table 2). The larger drag increases the deep water dissipation in the Atlantic at the expense of the bottom drag dissipation in shallow water, causing a larger discrepancy with TPXO.

In contrast to the spatially varying scale factor, the inclusion of synthetic abyssal hills does not significantly improve the tidal solution relative to the reduced Nycander scheme without abyssal hills: the RMSE for the most optimal solution is only weakly lowered in the Atlantic and Indian Oceans, where abyssal hills are mostly found (compare red and cyan circles in Fig. 8). The inclusion of the abyssal hills increases the global drag strength, leading to a reduction in scale factor from 3 to 2.5 , and also moves the global optimal solution closer to the optimal solution for the Atlantic in Fig. 8(a) and (b). Apparently, in order to reduce the RMSE in the Atlantic, the inclusion of roughness in deeper water via abyssal hills is not sufficient. The drag also needs to be increased in intermediate depths, which can be accomplished with a scale factor.

Iterating the SAL lowers the RMS error and can bring the dissipation into closer agreement with TPXO. The results for the iterated JSL scheme and the reduced Nycander scheme with abyssal hills are similar to the reduced Nycander scalar without abyssal hills and are not shown in Fig. 8 to avoid clutter.

\subsection{Regional response}

Finally, in Fig. 9 we compare the TPXO dissipation rates for regions outlined in Egbert and Ray (2001) with the dissipation rates for the optimally tuned Nycander scalar reduced at supercritical slopes (red triangle), the Nycander scalar with abyssal hills reduced at supercritical slopes (cyan circle), and the JSL scalar (black asterisk), all with iterated SAL. The regions numbered 1-28 (labeled AI) include shallow (deep) water dissipation sites. The horizontal bars in Fig. 9(a) mark the minimum and maximum dissipation rates computed over TPXO4a, TPX06.2, TPX07.2, and TPXO8-atlas. The TPXO4 rates are taken from Table 2 in Egbert and Ray (2001). The difference between the HYCOM dissipation rate and the mean dissipation rate computed over the four TPXO values is in Fig. 9(b).

Overall, the performance of the three simulations with iterated SAL is similar, and the HYCOM dissipation rates generally fall within the range of TPXO rates (Fig. 9(a)). The Hudson shelf and the MidAtlantic Ridge feature the largest spread in TPXO dissipation rates. While the HYCOM dissipation rates differ by about 25-50 GW with the mean TPXO dissipation rate for the Hudson shelf (Fig. 9(b)), they are in better agreement with TPXO8-atlas (Fig. 9(a)).

The effect of the abyssal hill roughness is the most obvious in the Atlantic, where the agreement with the mean TPXO rates improves for the Hudson and European shelves compared to the case with no abyssal hills. On the other hand, the additional roughness increases the dissipation for the Mid Atlantic Ridge, as well as the discrepancy with the mean TPXO rate (Fig. 9(b)).

The mean differences between the HYCOM and mean TPXO dissipation rates are $3.5,2.8$, and $2.3 \mathrm{GW}$ and the standard deviations of this difference are 17.8, 16.4, 16.6 GW for the reduced Nycander scalar, the reduced Nycander scalar with abyssal hills, and the JSL scalar, respectively. Hence, we conclude that the reduced Nycander scalar with abyssal hills performs better than the reduced Nycander scalar and that its performance is comparable to JSL for the regions in Fig. 9.

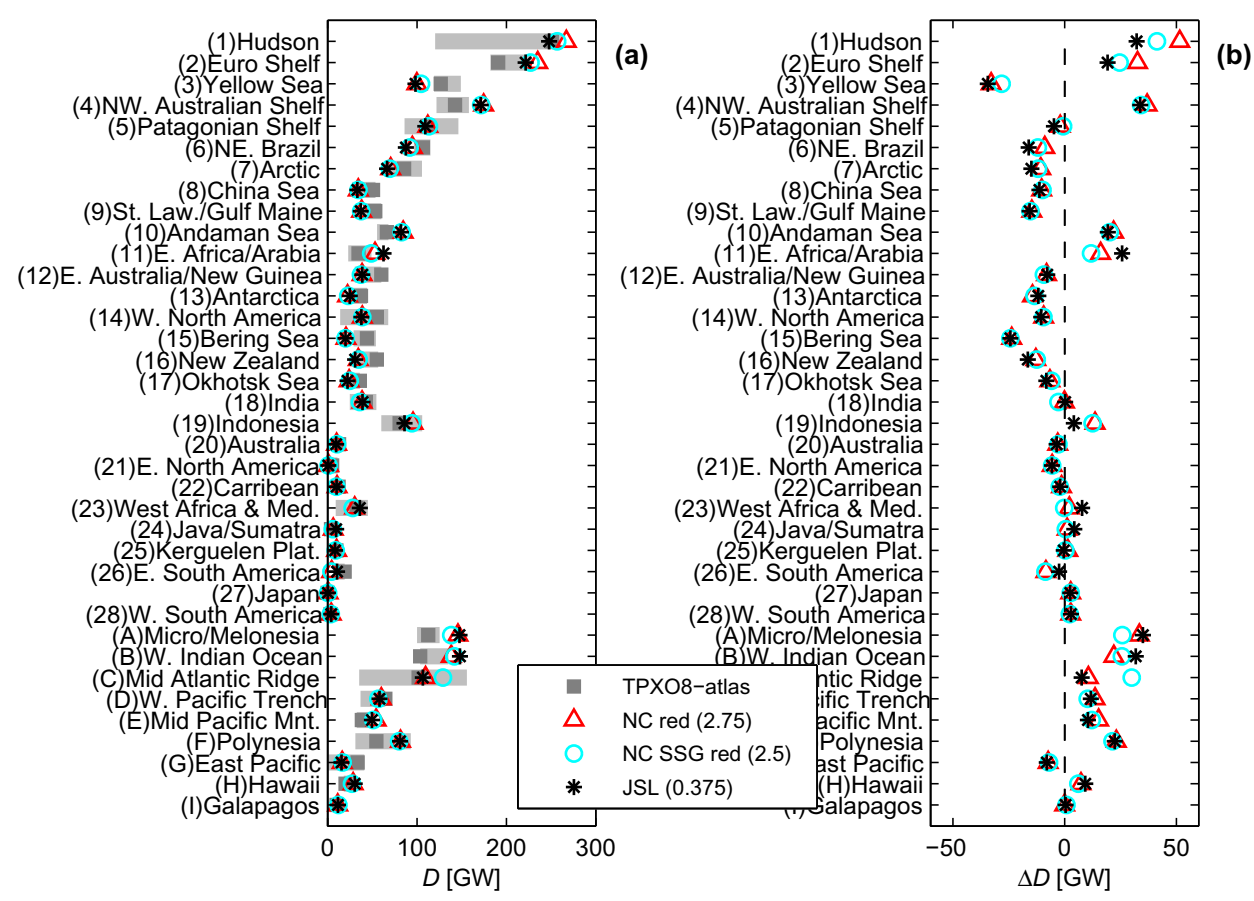

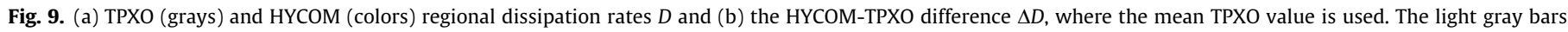

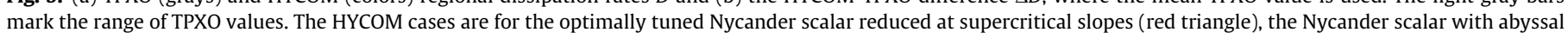

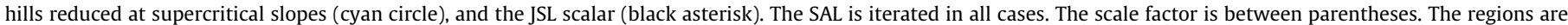

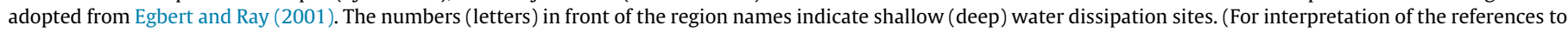
color in this figure legend, the reader is referred to the web version of this article.) 


\section{Discussion and conclusions}

This study documents several new approaches and/or findings that have to our knowledge not been published before. We have done an in-depth tuning in a barotropic model for dissipation, globally, regionally, and with depth, at the same time as we tune for elevation RMS errors. We have found that a scalarized tensor wave drag performs as well or better than the tensor equivalent. We have successfully applied a new empirical reduction of the linear wave drag strength at supercritical slopes in a barotropic model. Finally, we have computed a Nycander scalar drag for a bathymetry with additional artificial abyssal hill roughness and applied this drag in a barotropic model.

In this study we have shown that in order to get the lowest RMS error with respect to TPXO8-atlas $\mathrm{M}_{2}$ elevations, a tuned internal wave drag scheme has to be applied in our barotropic HYCOM set up. This conclusion is consistent with conclusions reached by others, e.g. Jayne and St. Laurent (2001), Arbic et al. (2004), Egbert et al. (2004) and Lyard et al. (2006). Although Green and Nycander (2013) compared the performance of the Jayne and St. Laurent (2001) and Nycander (2005) schemes in a barotropic model, they did not demonstrate whether their RMS elevation errors and dissipation rates could be improved by applying a scale factor. The strength of the internal wave drag may differ compared to that in other studies depending on the stratification, bathymetry, the horizontal resolution of the bathymetry data set, the barotropic model, how the drag is implemented in the model, etc. Moreover, the linear drag schemes overestimate the dissipation at supercritical topography. The overall drag strength is reduced after applying a correction at supercritical slopes. These are all practical reasons for applying a scale factor when implementing the schemes.

The original Nycander scheme is a tensor, the components of which describe the directionality of the topographic roughness. We find that the tensor does not perform better than the scalar. This is to be expected, because the semidiurnal velocities in the tensor and scalar simulations have similar directions and magnitudes as the TPXO8-atlas velocities, on which the scalar scheme is based. Hence, both simulations have similar dissipation rates as TPXO. The simulations with the scalar scheme have slightly lower RMS errors than the simulation with the tensor scheme. This may be because the scalar scheme is based on TPXO8-atlas velocities instead of model velocities. The former may be closer to the "truth" than the latter.

Nycander (2005), Green and Nycander (2013) and Green and David (2013) found that at supercritical slopes the untuned Nycander scheme overestimates the dissipation. Applying the unmodified scalar scheme and a small scale factor of 1.25 , we find that in intermediate water depths of 500 to $3000 \mathrm{~m}$ the dissipation rates are larger than in TPXO, while in deeper water they are smaller (Fig. 7). Moreover, with this scheme the simulation does not have the lowest elevation RMS error. We obtain lower RMS errors for a larger scale factor when the Nycander drag at supercritical slopes is reduced by the criticality squared (Nikurashin and Ferrari, 2011; Scott et al., 2011; Melet et al., 2013). The optimally tuned scheme is more in accordance with the TPXO dissipation depth profile than the full Nycander scheme (Fig. 7). Since this modified scheme has less drag, it needs to be amplified by a factor of about 2.25 to obtain the same dissipation rate as the unmodified scalar scheme. The reduction in dissipation for the same scale factor of 1.25 is about $25 \%$ from the unmodified to the reduced scheme. This is comparable to the reduction in barotropic energy conversion of 33\% found by Melet et al. (2013). Melet et al. (2013) applied the Nycander tensor to SRTM30_PLUS bathymetry with abyssal hills and TPXO velocities to analytically compute global barotropic to baroclinic conversion rates. Melet et al. (2013) computed 1.5 TW of dissipation for the full Nycander scheme with a capping of $10 \mathrm{~W} \mathrm{~m}^{-2}$ and $1.0 \mathrm{TW}$ when the empirical reduction was applied. The reduction in drag strength in shallow water for the JSL scheme also causes lower RMS errors similar to the empirical reduction for the Nycander scheme. However, in contrast to the reduced Nycander scheme, the JSL scheme has a dissipation depth profile that strongly deviates from TPXO in depths shallower than $3000 \mathrm{~m}$ (Fig. 7).

The application of the Nycander scalar to a bathymetry with additional abyssal hill roughness on ocean spreading ridges mostly improves the agreement with TPXO dissipation rates, e.g. Figs. 7 and 9, without improving the elevation RMS error (Table 2). The inclusion of abyssal roughness on the Mid Atlantic Ridge causes a noticeable increase of about $20 \%$ in the barotropic energy conversion, more so than on the spreading ridges in the Indian Ocean (compare regions C and B in Fig. 9). The Mid Atlantic Ridge has more supercritical abyssal hills than the spreading ridge in the Indian Ocean, causing a larger (relative) increase in the dissipation. These findings agree with numerical (Timko et al., 2009) and analytical (Melet et al., 2013) studies. Timko et al. (2009) applied SRTM30_PLUS bathymetry with abyssal hills in 3D HYCOM and found global and regional increases of conversion rates compared to simulations with only SRTM30_PLUS of 5-10\% and up to $25 \%$, respectively. Melet et al., 2013 found mostly regional increases of up to $60 \%$ after critical slope corrections were applied.

Of all basins, the Atlantic Ocean has the largest RMS error (Figs. 2 and 8). Moreover, its response to the tuning of the various drag schemes differs from the Pacific and Indian Oceans. For example, the full Nycander scalar is the best performing drag scheme in the Atlantic, but not in the other ocean basins (Fig. 8). Despite this, the tuning of the drag schemes in the global ocean in Fig. 6 resembles the tuning in the Pacific and Indian Oceans, validating our conclusions inferred from Fig. 6. Compared to the optimally tuned simulations, the RMS errors in the Atlantic can only be lowered for larger scale factors, i.e., when the drag strength and dissipation are increased. While the integral of all ocean basins is optimally tuned, this is not the case for all ocean basins when looked at individually: tuning one basin increases the error in the other. Hence, we apply a spatially varying scale factor to increase the drag in the Atlantic only. Although this lowers the RMS error by $0.6 \mathrm{~cm}$ in the Atlantic and by $0.2 \mathrm{~m}$ globally, the RMS error is still $2-3 \mathrm{~cm}$ larger than in the Pacific and Indian Oceans. Moreover, the discrepancy with the TPXO dissipation rates has increased. Although the inclusion of abyssal hills causes a rougher Atlantic seafloor, the improvement of the tidal solution is marginal compared to the effect of a spatially varying scale factor. Both a spatially varying scale factor and the inclusion of abyssal hill topography do not significantly reduce the RMS error in the Atlantic compared to the other basins. These large errors may be attributed to the inability of the model to correctly simulate the known large semidiurnal tidal resonances in the North Atlantic (Wunsch, 1972). The North Atlantic resonances yield large tide model sensitivities to bathymetry and coastal geometry. For instance, Arbic et al. (2009) showed that the blocking of Hudson Strait greatly alters tidal solutions in the northern Atlantic. Bathymetry is imperfectly known and represented in models, and is thus a likely cause of large errors in the North Atlantic. This is shown in sensitivity experiments by Egbert et al. (2004), who found RMS errors up to $7 \mathrm{~cm}$ for the deep ocean when depths were randomly perturbed by up to $10 \%$.

In the tuning experiments with a spatially varying scalar self attraction and loading (SAL) term, the global energy input is about 0.1 TW larger than in the TPXO8-atlas. Iterating the SAL lowers the RMS error and the energy input, and brings the dissipation rates more into agreement with TPXO. The reduced Nycander scalar with and without abyssal hills and the JSL parameterization with iterated SAL yield similar elevation RMS errors, but the simulations 
with the reduced Nycander schemes, in particular the one with abyssal hills, have a better agreement with the TPXO dissipation rates. The schemes with iterated SAL still dissipate more (less) energy in deeper (shallower) water than TPXO8-atlas (Table 2), and other data-assimilative barotropic tide models such as FES2004 (Lyard et al., 2006) and HAMTIDE (Taguchi et al., 2014). For example, for the reduced Nycander with iterated SAL $43 \%$ of the total dissipation occurs in deep water, whereas for TPXO8-atlas this is 36\%. On the one hand, this discrepancy between TPXO and the optimally tuned simulations in deep and shallow water dissipation rates may be attributed to the uncertainty in the TPXO dissipation rates, which can be negative. On the other hand, the weaker predictability of the currents compared to the elevations may also lead to (spatial) differences in dissipation rates. Moreover, the spatial distribution of the energy dissipation may improve as the elevation RMS error of the simulations is further reduced.

We compare our best RMS error with published results in Table 3. The studies by Jayne and St. Laurent (2001) and Shriver

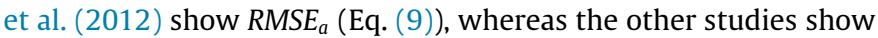
RMSE (Eq. (8)). To our knowledge, the RMS error with TPXO8-atlas obtained with our forward barotropic model is among the lowest published for forward barotropic and baroclinic tide models. When compared to the 151 pelagic tide gauges, the simulation with the reduced Nycander scheme with abyssal hill roughness is the best performing solution, but the difference with the simulation with the reduced Nycander scheme is within a few $\mathrm{mm}$. The inclusion of an iterated SAL as well as the extension of the southern domain improves the RMS error significantly compared to the HYCOM set up used in Shriver et al. (2012). Isopycnal multi-layer models, e.g. by Simmons et al. (2004a), Arbic et al. (2004), Arbic et al. (2010) and Shriver et al. (2012), need to apply internal wave drag to reduce the RMS errors. These models mostly resolve the low vertical modes. The linear wave drag is needed to account for the conversion of barotropic energy to high-mode internal waves and turbulent lee-waves, which are not resolved in these relatively coarse resolution models (Arbic et al., 2004).

In a next step we will apply the linear wave drag to the next generation of multi-layer HYCOM simulations having both atmospheric and tidal forcing. We will investigate how much of the barotropic to baroclinic energy conversion is resolved and how much needs to be parameterized with schemes similar to the ones evaluated in this study.

\section{Acknowledgments}

M.C. Buijsman, A.J. Wallcraft, J.F. Shriver, and J.G. Richman gratefully thank the "6.2 Eddy Resolving Global Ocean Prediction Including Tides" project sponsored by the Office of Naval Research under program element 0602435 N. R.W. Helber acknowledges support from the Office of Naval Research under program element $61153 \mathrm{~N}$ "6.1 The Impact of Spice on Ocean Circulation". B.K. Arbic and P.G. Timko acknowledge support from Naval Research Laboratory contract N000173-06-2-C003 and ONR grants N00014-09-1-1003 and N00014-11-1-0487. J.A.M. Green received funding from the UK Natural Environmental Research Council (Grant NE/F014821/1) and from the Climate Change Consortium for Wales. Last, but not least, we acknowledge A. Melet for sharing the abyssal hill data.

\section{References}

Accad, Y., Pekeris, C.L., 1978. Solution of the tidal equations for the $\mathrm{M}_{2}$ and $\mathrm{S}_{2}$ tides in the world oceans from a knowledge of the tidal potential alone. Philos. Trans. R. Soc. London Ser. A Math. Phys. Sci. 290, 235-266.

Arbic, B.K., Garner, S.T., Hallberg, R.W., Simmons, H.L., 2004. The accuracy of surface elevations in forward global barotropic and baroclinic tide models. Deep Sea Res. II 51, 3069-3101.
Arbic, B.K., Karsten, R.H., Garrett, C., 2009. On tidal resonance in the global ocean and the back-effect of coastal tides upon open-ocean tides. Atmos. Ocean 47, 239-266.

Arbic, B.K., Wallcraft, A.J., Metzger, E.J., 2010. Concurrent simulation of the eddying general circulation and tides in a global ocean model. Ocean Modell. 32, 175187.

Becker, J.J., Sandwell, D.T., Smith, W.H.F., Braud, J., Binder, B., Depner, J., Fabre, D. Factor, J., Ingalls, S., Kim, S.H., Ladner, R., Marks, K., Nelson, S., Pharaoh, A Trimmer, R., Rosenberg, J.V., Wallace, G., Weatherall, P., 2009. Global bathymetry and elevation data at 30 arc seconds resolution: SRTM30PLUS. Mar. Geod. 32, 355-371.

Bell, T.H., 1975. Topographically generated internal waves in the open ocean. J. Geophys. Res. 80, 320-327.

Bleck, R., 2002. An oceanic general circulation model framed in hybrid isopycnic cartesian coordinates. Ocean Modell. 4, 55-88.

Carnes, M.R., Helber, R.W., Barron, C.N., Dastugue, J.M., 2010. Validation test report for GDEM4. Technical Report Memorandum Report, 7330-10-9271. Navy Research Laboratory, Stennis Space Center, MS 39529-5004.

Egbert, G.D., Ray, R.D., 2000. Significant dissipation of tidal energy in the deep ocean inferred from satellite altimeter data. Nature 405, 775-778.

Egbert, G.D., Ray, R.D., 2001. Estimates of $\mathrm{M}_{2}$ tidal energy dissipation from TOPEX/ Poseidon altimetry data. J. Geophys. Res. 106, 22,475-22,502.

Egbert, G.D., Ray, R.D., 2003. Semi-diurnal and diurnal tidal dissipation from TOPEX Poseidon altimetry. Geophys. Res. Lett. 30. http://dx.doi.org/10.1029/ 2003GL017676.

Egbert, G.D., Bennett, A.F., Foreman, M.G.G., 1994. TOPEX/POSEIDON tides estimated using a global inverse model. J. Geophys. Res. 99, 24821-24852.

Egbert, G.D., Ray, R.D., Bills, B.G., 2004. Numerical modeling of the global semidiurnal tide in the present day and in the last glacial maximum. J. Geophys. Res. 109. http://dx.doi.org/10.1029/2003JC001973.

Foreman, M.G.G., 1977. Manual for tidal heights analysis and prediction. Technical Report Pacific Marine Science Report 77-10. Institute of Ocean Sciences. Patricia Bay, Sidney, BC.

Garner, S.T., 2005. A topographic drag closure built on an analytical base flux. J. Atmos. Sci. 62, 2302-2315.

Goff, J.A., Arbic, B.K., 2010. Global prediction of abyssal hill roughness statistics for use in ocean models from digital maps of paleo-spreading rate, paleo-ridge orientation, and sediment thickness. Ocean Modell. 32, 36-43.

Green, J.A.M., David, T.W., 2013. Non-assimilated tidal modeling of the South China Sea. Deep Sea Res. I 78, 42-48.

Green, J.A.M., Nycander, J., 2013. A comparison of tidal conversion parameterizations for tidal models. J. Phys. Oceanogr. 43, 104-119.

Hendershott, M.C., 1972. The effects of solid earth deformation on global ocean tides. Geophys. J. R. Astron. Soc. 29, 389-402.

Jayne, S.R., St. Laurent, L.C., 2001. Parameterizing tidal dissipation over rough topography. Geophys. Res. Lett. 28, 811-814.

Le Provost, C., Genco, M.L., Lyard, F., Vincent, P., Canceil, P., 1994. Spectroscopy of the world ocean tides from a finite element hydrodynamic model. J. Geophys. Res. 99, 24777-24797.

Lyard, F., Lefevre, F., Letellier, T., Francis, O., 2006. Modelling the global ocean tides: modern insights from FES2004. Ocean Dyn. 56, 394-415.

Melet, A., Nikurashin, M., Muller, C., Falahat, S., Nycander, J., Timko, P.G., Arbic, B.K. Goff, J.A., 2013. Internal tide generation by abyssal hills using analytical theory. J. Geophys. Res. 118, 6303-6318. http://dx.doi.org/10.1002/2013JC009212.

Müller, M., Cherniawsky, J., Foreman, M., von Storch, J.S., 2012. Global map of $\mathrm{M}_{2}$ internal tide and its seasonal variability from high resolution ocean circulation and tide modelling. Geophys. Res. Lett. 39. http://dx.doi.org/10.1029/ 2012GL053320.

Munk, W.H., 1966. Abyssal recipes. Deep Sea Res. 13, 707-730.

Munk, W.H., Wunsch, C., 1998. Abyssal recipes. II: Energetics of the tides and wind. Deep Sea Res. 45, 1976-2009.

Murray, R.J., 1996. Explicit generation of orthogonal grids for ocean models. J. Chem. Phys. 126, 251-273.

Nikurashin, M., Ferrari, R., 2011. Global energy conversion rate from geostrophic flows into internal lee waves in the deep ocean. Geophys. Res. Lett. 38. http:/ dx.doi.org/10.1029/2011GL046576.

Nycander, J., 2005. Generation of internal waves in the deep ocean by tide. J. Geophys. Res. 110. http://dx.doi.org/10.1029/2004JC002487.

Pugh, D.T., 1987. Tides, Surges and Mean Sea-Level. A Handbook for Scientists and Engineers. Wiley, Chichester.

Ray, R.D., 1998. Ocean self-attraction and loading in numerical tidal models. Mar. Geod. 21, 181-192.

Ray, R.D., 2013. Precise comparisons of bottom-pressure and altimetric ocean tides J. Geophys. Res. 118, 4570-4584. http://dx.doi.org/10.1002/jgrc.20336.

Sandwell, D.T., Smith, W.H.F., 2009. Global marine gravity from retracked Geosat and ERS-1 altimetry: ridge segmentation versus spreading rate. J. Geophys. Res. 114. http://dx.doi.org/10.1029/2008JB006008.

Schlichting, H., 1968. Boundary Layer Theory. McGraw-Hill, New York.

Schwiderski, E.W., 1980. On charting global ocean tides. Rev. Geophys. 18, 243-268.

Scott, R.B., Goff, J.A., Garabato, A.C.N., Nurser, A.J., 2011. Global rate and spectral characteristics of internal gravity wave generation by geostrophic flow over topography. J. Geophys. Res. 116. http://dx.doi.org/10.1029/2011JC007005.

Shriver, J.F., Arbic, B.K., Richman, J.G., Ray, R.D., Metzger, E.J., Wallcraft, A.J., Timko, P.G., 2012. An evaluation of the barotropic and internal tides in a high resolution global ocean circulation model. J. Geophys. Res. 117. http:/ dx.doi.org/10.1029/2012JC008170. 
Shum, C.K., Woodworth, P.L., Andersen, O.B., Egbert, G.D., Francis, O., King, C. Klosko, S.M., Provost, C.L., Li, X., Molines, J.M., Parke, M.E., Ray, R.D., Schlax, M.G., Stammer, D., Tierney, C.C., Vincent, P., Wunsch, C.I., 1997. Accuracy assessment of recent ocean tide models. J. Geophys. Res. 102, 25,17325,194 .

Simmons, H.L., Hallberg, R.W., Arbic, B.K., 2004a. Internal wave generation in a global baroclinic tide model. Deep Sea Res. II 51, 3043-3068.

Simmons, H.L., Jayne, S.R., St. Laurent, L.C., Weaver, A.J., 2004b. Tidally driven mixing in a numerical model of the ocean general circulation. Ocean Modell. 6, 245-263.

Stammer, D., Ray, R.D., Andersen, O.B., Arbic, B.K., Bosch, W., Carrère, L., Cheng, Y., Chinn, D.S., Dushaw, B.D., Egbert, G.D., Erofeeva, S.Y., Fok, H.S., Green, J.A.M., Griffiths, S., King, M.A., Lapin, V., Lemoine, F.G., Luthcke, S.B., Lyard, F., Morison, J., Müller, M., Padman, L., Richman, J.G., Shriver, J.F., Shum, C.K., Taguchi, E., Yi, Y., 2014. Accuracy assessment of global barotropic ocean tide models. Rev. Geophys. 52. http://dx.doi.org/10.1002/ 2014RG000450.
Stigebrandt, A., 1999. Resistance to barotropic tidal flow in straits by baroclinic wave drag. J. Phys. Oceanogr. 29, 191-197.

Taguchi, E., Stammer, D., Zahel, W., 2014. Inferring deep ocean tidal energy dissipation from the global high-resolution data-assimilative HAMTIDE model. J. Geophys. Res. 119, 4573-4592. http://dx.doi.org/10.1002/2013JC009766.

Taylor, G.I., 1919. Tidal friction in the Irish Sea. Philos. Trans. R. Soc. London 220, $1-$ 33.

Timko, P.G., Arbic, B.K., Goff, J.A., 2009. The effect of statistical abyssal hill roughness on the generation of internal waves. in: Paper Presented at 14th Layered Ocean Model meeting, Miami, FL, USA.

Wunsch, C., 1972. Bermuda sea level in relation to tides, weather, and baroclinic fluctuations. Rev. Geophys. 10, 1-49.

Zaron, E.D., Egbert, G.D., 2006. Estimating open-ocean barotropic tidal dissipation: the Hawaiian Ridge. J. Phys. Oceanogr. 36, 1019-1035.

Zilberman, N.V., Becker, J.M., Merrifield, M.A., Carter, G.S., 2009. Model estimates of $M_{2}$ internal tide generation over Mid-Atlantic Ridge topography. J. Phys. Oceanogr. 39, 2635-2651. 